\title{
Interaction mechanisms in small-scale model MSE walls under the strip footing load
}

Type of Paper: Original research paper (Geosynthetics International)

\author{
Hamzeh Ahmadi \\ Corresponding author, PhD, Ghent University, Department of Civil Engineering, Laboratory of \\ Geotechnics, Technologiepark 905, B-9052 Gent, Belgium. \\ Email: hamzeh.ahmadi@ugent.be \& hamzeh.ahmadi@gmail.com \\ Tel. +32 9 2645728; Mobile. +32475662292; Fax. +3292645849.
}

\begin{abstract}
Adam Bezuijen
Professor, Ghent University, Department of Civil Engineering, Laboratory of Geotechnics, Technologiepark 905, B-9052 Gent, Belgium and

Deltares, Delft, The Netherlands

Email:adam.bezuijen@ugent.be

Tel. +329 2645721; Fax. +3292645849
\end{abstract}

Jorge G. Zornberg

Professor, The University of Texas at Austin, Department of Civil, Architectural and

Environmental Engineering,

Austin, TX, 78712, USA

Email:zornberg@mail.utexas.edu

Tel. +15122323295 
KEYWORDS: Geosynthetics, scaled MSE model tests, Strip footing load, Preloading, Analytical analysis, Particle image velocimetry (PIV).

\begin{abstract}
The effect of preloading on Mechanically Stabilized Earth (MSE) has remained an aspect difficult to quantify in design, particularly when considering different reinforcement types, stiffness values, and facing rigidity. This study analyses several scaled model tests on Mechanically Stabilized Earth (MSE) walls under a strip footing load with a single unloading-reloading cycle. Scaled models were constructed as part of this investigation to expand the evaluation of previously constructed full-scale tests. The strip footing load and wall deflections were measured and compared with analytical models. The failure mechanism of the soil, before and after the strip footing load, was included in the study via the Particle Image Velocimetry (PIV) method. The results indicate that the bearing capacity of a strip footing is higher for a rigid facing than for a flexible facing. PIV analysis results for the first and second loading step formed two failure lines with the angle $\left(\frac{\pi}{4}+\frac{\varphi}{2}\right)$. The deflection values in the second loading step, however, were smaller than those reached during the first loading in small-scale tests. Good agreement was observed between the proposed analytical method and experimental results for the second loading step, after taking into account the preloading effect.
\end{abstract}




\section{INTRODUCTION}

In many situations, footings are located on the backfill of retaining structures (e.g. footings on bridge abutments or roads located on top of the retaining structure). The behaviour of reinforced earth structures under a strip footing load has been studied through full-scale physical models and laboratory model tests (Adams 1997; Gotteland et al. 1997; Ketchart and Wu 1997; Wu et al. 2001; Abu-Hejleh et al. 2002; Lee and Wu 2004; Adams et al. 2011; Bourgeois et al. 2011; Ahmadi and Hajialilue-Bonab, 2012; Allen and Bathurst, 2015; Xiao et al. 2016; Ahmadi and Bezuijen 2018; Zornberg et al. 2019; Allen and Bathurst, 2019; Bathurst, 2020 ).

For a footing constructed behind a reinforced earth wall, the maximum bearing capacity will depend on a number of factors (Ahmadi and Hajialilue-Bonab, 2012 and Xiao et al. 2016), including: (1) the location of the footing in relation to the wall; (2) the type of reinforcement; (3) the number of reinforcement layers; (4) the depth to the first reinforcement layer below the footing; (5) the spacing between reinforcement layers; and (6) the dimensions of the reinforcement as compared with the dimensions of the wall.

A recent study by Ahmadi and Bezuijen (2018) showed that facing panel rigidity and base restriction can have a significant effect on wall deflections and loads in the reinforcement layers. Tatsuoka (1992) showed that the facing rigidity in reinforced soil walls has a significant effect on the distribution of tensile forces induced in the reinforcement without surcharge loading. In the Tatsuoka (1992) study, the largest tensile forces occurred close to the wall face for a reinforcement with good connection to a rigid facing, while the largest tensile forces were measured farther away from the wall face where there was no connection or the connection force was small.

Pham (2013) found out that the influence of reinforcement strength in bearing capacity of GRS systems is less significant than spacing. For reinforced soil walls only (without a strip footing load), Ho and Rowe (1996) and Rowe and Ho (1997) found that reinforcement stiffness, vertical spacing and the length-to-wall-height ratio $(\mathrm{L} / \mathrm{H})$ are important parameters that affect wall displacement.

In MSE walls during compaction, unloading-reloading cycles occur as part of the backfill placement. This construction step decreases lateral wall deflections and settlements under subsequent surcharge loads. In reinforced soil retaining walls, the compaction loads increase the lateral earth pressures close to the facing panels. The increased lateral earth pressures are transferred to the reinforcement layers by frictional or bearing interaction mechanisms. The necessary deformation for mobilization of the ultimate frictional and bearing resistance in geosynthetic (extensible) material is also comparatively large (Teixeira et al., 2007).

Consequently, the reinforcement layers elongate under the added compaction-induced lateral earth pressures. The elongated reinforced layer remains in the pre-stressed condition after removing compaction loads as the increased soil densification prevents stress relieving (Lackner et al. 2013). This phenomenon has been considered to improve the deformation characteristics of the MSE walls or bridge abutments by applying static or dynamic loads as a preloading surcharge to mobilize the reinforcement layers within the soil mass by prestressing them. The approach is expected to result in comparatively smaller wall deflections and footing settlements under subsequently applied surcharge loads. A related experience was reported by Ahmadi and Bezuijen (2018), which involved localized dynamic preloading before the subsequent static loading with a strip footing placed over full-scale MSE walls. The results showed that without preloading, the lateral wall deflections were essentially twice those obtained when considering a dynamic preloading.

The location of maximum tensile loads is a key assumption in the design of geosynthetic reinforced soil wall systems loaded with strip footings. The AASHTO design method considers that the locus 
of maximum tensile forces starts at the wall toe and shifts to intersect the back of the footing at the top of the wall (e.g. a bridge seat). The maximum tensile force in each reinforcement layer is calculated along the failure surface using empirical approaches such as the $2 \mathrm{~V}: 1 \mathrm{H}$ method. However, the impact on this locus on variables such as reinforcement characteristics, reinforcement spacing, facing rigidity, and preloading requires further investigation.

Specifically, limited research has been conducted on the behaviour of Mechanically Stabilized Earth (MSE) walls under a strip footing load considering different reinforcement layers stiffnesses and types, different facing panel rigidities and preloading effects.

Furthermore, for these types of structures, limited experimental data sources exist that evaluate changes in failure mechanism when the facing panel rigidity and reinforcement types are varied under a single unloading-reloading cycle.

This paper presents a series of instrumented reduced-scale models, the evaluation of which is useful to assess the influence of facing panel rigidity, stiffness of the reinforcement layers and preloading on lateral wall deflections, strip footing settlements, vertical earth pressures and consequently, the maximum tensile force in the reinforcement layers. The effects of dynamic or static loading to improve subsurface soils by increasing their density and/or horizontal stresses are identified herein as the preloading effect.

\section{EXPERIMENTAL SET-UP}

\subsection{Model box and wall}

A series of experiments were conducted in a stiff metal test box with inner dimensions of $1 \mathrm{~m}$ in length, $0.8 \mathrm{~m}$ in width and $1 \mathrm{~m}$ in height. One side of the test box consisted of $30 \mathrm{~mm}$-thick toughened glass (with a tensile strength of $65 \mathrm{MPa}$ ) for observation and photographing the soil deformation during testing (see Fig. 1a). To minimize friction between the sidewalls of the box and backfill, several layers of thin, lubricated transparent plastic film were carefully installed to essentially isolate the soil mass from any frictional effects of the test box. The results of direct shear testing between sand and glass showed a friction angle of only $7.8^{\circ}$. The box was sufficiently rigid to maintain plane strain conditions in the reinforced retaining wall model. All tests were conducted with a wall height of $0.8 \mathrm{~m}$ and a reinforcement length of $0.6 \mathrm{~m}$. A smooth wooden plate was placed at the bottom of the box. Accordingly, the friction between the facing panel and base plate of the box was minimized in the small-scale tests (on the other hand, based on the numerical analysis results, the toe friction coefficient was considered as 0.2 in order to get the same wall movement in the base for the test and numerical analysis).

The test configurations are given in Fig. 1b. Three different types of reinforcements (geogrid, nonwoven and woven geotextiles) and two types of facing panels (full height rigid and flexible panel) were used in the tests. The flexible and rigid facing panels consisted of $3 \mathrm{~mm}$-thick and 50 mm-thick factory plywood plates, respectively $\left(\mathrm{EI}=28 \times 10^{-3}\right.$ and $130 \mathrm{kN} \cdot \mathrm{m}^{2} / \mathrm{m}$, respectively). Four Linear Variable Displacement Transducers (LVDTs) were used to measure the horizontal displacements of the wall. 


\subsection{Strip footing model and loading system}

The strip footing was made of steel welded plates in a channel shape with a length of $0.795 \mathrm{~m}$, a width of $0.2 \mathrm{~m}$, a height of $0.15 \mathrm{~m}$ and a thickness of $0.025 \mathrm{~m}\left(\mathrm{EI}=6.2 \times 10^{3} \mathrm{kN} . \mathrm{m}^{2}\right)$. The length of the footing and width of the test box were made to be nearly equal to maintain plane strain conditions. The two ends of the footing plate were covered with smooth plastic to minimize end friction effects. After filling the box with compacted sand, the surface of the sand was levelled, and the model footing was placed on the predetermined location. A $100 \mathrm{kN}$ load cell placed between the hydraulic jack and reaction beam recorded the magnitude of loads applied to the footing at a constant displacement rate. The load from the hydraulic jack was transferred concentrically to the footing. A pressure gauge $200 \mathrm{~mm}$ in diameter (for vertical stress measurements) was placed horizontally at $\mathrm{z}=0.8 \mathrm{~m}$ in the centreline of the strip footing on the bottom of the container (see Fig. 1b). The vertical displacements of the model footing were measured by two LVDTs located at the front and centreline of the strip footing. To study the effects of preloading and pre-stressed conditions on the models, a reloading step was applied in every test to the strip footing load following the first load. In the model tests, after unloading of the strip footing load, a second load (reloading) was applied to models, to study the effect of the preloading on the wall deflection under the strip footing load. A cross-section is shown in Fig. 1b.

\subsection{Soil and reinforcement}

The soil used in this study was a dry sand that classifies as SP (poorly graded sand) with no fines according to the Unified Soil Classification System (USCS). The particle size distribution was characterized via the dry sieving method and the results are presented in Fig. 2. Because of intergrain colour variation, images of the sand displayed a wide spectrum of intensity values. A favourable spatial distribution of brightness provided well-textured images for PIV analysis. Table 1 presents the properties of the sand. Soil layers were placed every $0.025 \mathrm{~m}$ and compacted by a hand-held electric compactor (Wacker) until the final wall height was achieved. The backfill soil for all tests was compacted using a small vibrating plate compactor, which provided a uniform backfill with an average unit weight of $15.72 \mathrm{kN} / \mathrm{m}^{3}$ and a relative density of $88 \%$. The friction angle obtained from direct shear tests at the same relative density of the model tests was $40.5^{\circ}$. Following soil compaction, reinforcements were placed on the surface of the sand at each predetermined depth. Three different types of reinforcements were used in this study, including a highly extensible nonwoven geotextile, a less deformable geogrid and a woven geotextile. Tensile tests were conducted on the specimens in the longitudinal direction and the results are given in Fig. 3. The properties of the reinforcements selected are shown in Table 1. The stiffness of geogrid layer used in the models is $1 / 5$ of that used in the full-scale reinforced soil structures reported by Ahmadi and Bezuijen (2018). On the other hand, the stiffness of woven geotextiles is similar to the geogrid reinforcements in the small-scale models. Finally, the stiffness of the nonwoven geotextile was 10 times smaller than the geogrid layers used in small-scale models to reach the ultimate bearing capacity of strip footing load.

\subsection{Model characteristics}

A series of tests were conducted in which the number and vertical spacing of the reinforcement layers $\left(\mathrm{N}\right.$ and $\left.\mathrm{S}_{v}\right)$, reinforcement type and wall facing panel rigidity were varied, while the distance 
of the strip footing from the wall face (b), length of the reinforcement layers (L) and width of the strip footing load (B) were fixed.

Table 2 summarizes the various test conditions. Additional parameters were adopted to define the facing panel rigidity and loading steps for the reinforced soil models: F and R represent the flexible and rigid faces, respectively, and 1 and 2 represent the first loading and second loading step, respectively.

\section{TYPES OF FAILURE IN SOIL UNDER STRIP FOOTING LOAD}

According to Plumey et al. (2011) and Ahmadi and Hajialilue-Bonab (2012), the failure mechanism in the soil for a flexural retaining structure fixed to the base and linear footing is composed of a rigid body and plasticised (or shear) area delimited by logarithmic spirals. The critical slip surface of an MSE wall divides the reinforced zone into an active and resistant zone. The reinforcement lengths within the resistant zone provide pull-out resistance and the shear stresses in the active zone are directed outward and lead to a decrease in tensile forces. The critical slip surface in a reinforced soil wall is assumed to coincide with the maximum tensile force line in the failure step. In conventional MSE walls, the location of maximum tensile force depends primarily on the type of reinforcement used. In the case of inextensible reinforcements, the failure surface is assumed to be approximately bilinear and varies with depth. In the case of extensible reinforcements, the maximum tensile force surface is assumed to be approximately linear and pass through the toe of the wall (Berg et al., 2009).

In the case of MSE abutments, it has been observed that the locus of maximum tensile loads in the geotextiles may change depending mainly on the geometry of the footing (Schlosser and Bastick, 1991 and Brabant, 2001). The location of maximum tensile forces shifts to intersect the back of the bridge seat and wall toe based on the strip footing locations.

\subsection{Digital imaging and PIV method}

Using the PIV method as implemented by the image processing software GeoPIV (White et al. (2001), (2003) and (2005)), successive pairs of photographs were compared to determine incremental displacement and strain values. A Panasonic Lumix DMC-GH3 (16.1 megapixels) camera, positioned in front of the sidewall of the test box, facilitated visualisation of soil movement during testing and image processing. All controls, such as focus, gain and shutter speed, were automatically adjusted. Two projectors positioned on both sides of the camera at $45^{\circ}$ angles and one positioned above the camera's optical axis eliminated optical effects from the environment on the viewing window, thereby preventing errors caused by random variation in pixel intensity. The first step in PIV analysis is to divide the digital image into square patches of pixels to form a regular mesh. Because PIV precision is a function of patch size and grid spacing, an initial study of convergence and stability was performed using different patch sizes and grid spacings. According to Lesniewska and Wood (2009), Ahmadi and Hajialilue-Bonab (2012) and Ahmadi (2020), if the patch is too small, the amount of information captured may not allow the software to recognize the displaced patch with confidence, which may yield false displacement values. The next quantity that must be defined is the grid spacing used for successive displacement estimates within each image. Strain calculations require the differentiation of displacement information. A finer grid implies greater detail, but also a greater probability of erratic values. Consequently, the selection of an optimum patch size in PIV analysis necessitates a balance between two conflicting interests. Larger 
patches offer improved precision, whereas smaller patches ensure a greater number of measurement points in the image and reveal detail in areas with a high strain gradient. The best solution that provides a compromise between these problems is the use of relatively large, overlapping patches.

The displacement fields obtained for three different reinforcements are shown in Fig. 4 (the PIV analysis was conducted with a patch size of 64-by-64 pixels and a mesh spacing of 64). Soil tended to move toward the wall, with a well-defined failure zone in all cases. As depicted in the figure, the failure zone for the flexible reinforcement (nonwoven geotextile) was deeper than for the woven geotextile and geogrid, and the model with the woven geotextile had the widest failure zone. In the model with the nonwoven geotextile, the first reinforcement layer visibly pulled away from the soil.

Fig. 5 presents the total maximum shear strain distributions for the same tests shown in Fig. 4 . The PIV analysis was conducted with a patch size of 64-by-64 pixels and a mesh spacing of eight pixels in Fig. 5, Fig. 6, Fig. 7 and Fig. 8 (containing 102,543 patches and 232,766 elements).

The same range of total maximum shear strain $(0-30 \%)$ is plotted for all cases to facilitate a comparison of the results (strain localisation in these and other pictures clearly indicates where the failure occurred in soil).

This figure shows the effect of changing the reinforcement type while maintaining equal vertical displacement steps in the shear zones. The failure patterns in Fig. 5a, 5b and 5c are straight lines. There is a clear triangular failure shape in Fig. $5 \mathrm{c}$ as well as under the strip footing for the geogrid reinforcement. The failure lines in Fig. 5 were delineated by white dashed lines with an angle $\left(\frac{\pi}{4}+\right.$ $\frac{\varphi}{2}$ ) with the horizontal.

Two main failure lines with a tendency to move toward the wall were created in Fig. 5b and 5c: one with a shallow position and one with a deep position. These lines have the angle $\left(\frac{\pi}{4}+\frac{\varphi}{2}\right)$, but with different failure depths and originations. Fig. 5a and $5 \mathrm{~b}$ have deeper failure lines as compared to Fig. 5c. This indicates that the failure zone is deeper for the geotextile reinforcements with frictional interaction only than for the geogrid with smaller frictional and larger bearing interaction (the geogrid and woven geotextile have a 35\% difference in stiffness).

Considering the interaction phenomena between the reinforcements and soil displayed in these figures, the interacted area in the nonwoven geotextile (Fig. 5a) was limited around the failure line with the angle $\left(\frac{\pi}{4}+\frac{\varphi}{2}\right)$, but for the woven geotextile (Fig. 5b), this area continued to the end of the reinforcement layers.

The total maximum shear strains shown in Fig. 6a, 6b and 6c indicate different failure mechanisms for reinforced models with a rigid face. Fig. $6 a, 6 b$ and $6 \mathrm{c}$ display shear failures for configurations with a rigid wall that included nonwoven and woven geotextiles, and geogrid reinforcement layers, respectively. The first reinforcement layer in all figures was pulled away from the soil. The failures involving the nonwoven geotextile and geogrid layers were small and shallow, located over the third reinforcement layer. For the woven geotextile layers (Fig. 6b), the failure zones were larger and deeper than in Fig. 6a and 6c. Additionally, an incomplete shallow failure line over the second layer can be seen in Fig. 6b. The data presented in Fig. 5 and Fig. 6 reveal that the woven geotextile with greater stiffness exhibited the deeper failure line of the models than the nonwoven geotextile with more frictional interaction and the geogrid reinforcement.

As shown in Fig. 6, two failure lines with the angle $\left(\frac{\pi}{4}+\frac{\varphi}{2}\right)$ formed: one from the inner edge of the strip footing, with a tendency toward the wall face (shallow position), and another from the outer edge of the strip footing (deep position). A comparison of Fig. 5 and Fig. 6 indicates that the failure 
zones were deeper in the rigid wall models as compared to the failure zones measured in the flexible wall models with the woven geotextile and geogrid reinforcement. The vertical failure line close to the wall face in these figures shows the frictional interaction between the face and soil. This vertical line is clear for the rigid wall in Fig. 6. The combination of deeper failure line (with the angle $\left(\frac{\pi}{4}+\frac{\varphi}{2}\right)$ ) and triangular failure shape under the strip footing load in the rigid wall exhibited the higher ultimate bearing capacity.

Fig. 7 shows shear strains with a 64-by-64 pixel patch size and mesh spacing of eight pixels (the optimal patch size and mesh spacing established). Increasing the mesh refinement revealed shear strain maps that divided into several distinct zones. Shear strain zones that occurred between every step of the footing settlement were inspected using the incremental maximum shear strains (IMSS), which are based on PIV analysis results. This figure presents the results of a test in which eight nonwoven geotextile layers and a flexible facing panel were used. Step 1 in Fig. 7 shows shear zones after the struts in front of the wall were released, which occurred at a strain range of 0-10\%. Small strains that occurred between reinforcement layers were situated lower, as seen in this figure, revealing the confinement effect of the reinforcement layers in the horizontal direction (Ruiken et al., 2010). In steps 2 (after first loading) and 3 (after unloading), two straight failure lines emerged, originating from the outer and inner edges of the footing, with the angle $\left(\frac{\pi}{4}+\frac{\varphi}{2}\right)$, as delineated by the white dashed lines. The failure line from the outside of the footing was deeper than the inner failure line. In step 2 over the second layer of reinforcement, there was a failure zone similar to the general shear failure. Complete general shear failure occurred in step 4 (after reloading the sample) and causes a rotational movement in the strip footing (which shows that the applied pressure is close to the ultimate bearing capacity of strip footing).

Fig. 8 shows four steps of a test with 8 layers of nonwoven geotextile and the rigid wall that contain the shear zones from the IMSS output. In step 1 of this figure, there are small shear zones between the reinforcement layers that occurred in the higher position of the wall (compared to Fig. 7). In steps 2, 3 and 4, there is only a straight failure line emerged starting from the outside edge of the footing with the angle $\left(\frac{\pi}{4}+\frac{\varphi}{2}\right)$. In these steps and over the second layer of reinforcement, there is a uncomplete failure zone similar to the general shear failure and smaller than the zone shown in Fig. 7. In this step, the strip footing remained horizontal (showing that the applied pressure is smaller than the ultimate bearing capacity of strip footing). In the rigid wall compare to the flexible wall, there is a clear failure line generated between the soil and wall face in the vertical direction (soil-wall face frictional interaction).

From the PIV analysis results of Ahmadi and Hajialilue-Bonab (2012), for the flexural retaining structure fixed in the base, the failure mechanism in the soil was composed of two logarithmic spirals, but from this study for the mechanically stabilized earth walls with flexible and rigid faces, the failure zone has two main lines with the angle $\left(\frac{\pi}{4}+\frac{\varphi}{2}\right)$. Then, the base fixation of the flexible facing panel can change the shape of the failure zones from the linear to the spiral shape.

On the other hand, compared to AASHTO (line of the maximum tension under the strip footing load close to the MSE walls), the experimental models of this study showed different failure lines for different facing panel and reinforcement types. The failure zone from PIV analysis not only has an intersect with the wall face in upper position than wall base but also there are two parallel failure lines under the strip footing load. 


\section{MEASUREMENTS AND COMPARISON WITH ANALYTICAL METHODS}

\subsection{Vertical earth pressure}

The AASHTO method presented an empirical method to calculate the stresses in the soil near a vertical wall caused by a strip footing load. The vertical pressure as a function of depth behind the retaining structures is:

$$
\begin{cases}q_{v}=\frac{q \cdot B}{B+\mathrm{z}}, & \mathrm{z}<2 \mathrm{~b} \\ q_{v}=\frac{q \cdot B}{B+2 b}, & \mathrm{z} \geq 2 \mathrm{~b}\end{cases}
$$

where, $b=$ distance between the load and the wall, $B=$ width of the strip load, $z=$ vertical distance from the soil surface; $q=$ strip footing load $q_{v}=$ vertical stress in the depth due to the strip footing load.

Fig. 9 compares the measurements of vertical earth pressure at different stages of loading with the AASHTO method and the empirical $(2 \mathrm{~V}: 1 \mathrm{H})$ method $\left(q_{v}=\frac{q \cdot B}{B+z}\right)$. The vertical earth pressure is measured at the bottom of models during the first and second loading steps.

In Fig. 9a with 4 layers of different types of reinforcement, the measured values are closer to the AASHTO method except for the rigid wall with nonwoven geotextile.

To clarify this phenomenon (as shown later in Fig. 11), the largest wall deflection occurred on top of the rigid walls with nonwoven geotextile compared to others. However, the minimum wall movement occurred at the base of these two models. This suggests that the rigid face in these two models resulted in the largest rotation of the wall. Based on Coulomb's theory, by increasing the facing panel inclination, a larger part of the lateral earth pressure will be carried by the facing panel due to friction interaction. This higher frictional load acts upward, decreasing the vertical soil pressure transferred to the base.

The measured values in the second loading of the models are shown in Fig. 9b. The measured values are located between the empirical $(2 \mathrm{~V}: 1 \mathrm{H})$ method and the AASHTO method. It shows by reloading the model as there is a prestressed condition in reinforcement layers from the first loading step, less vertical soil pressure can be transferred to the base of the model from the facing panel.

On the other hand, Damians et al. 2014 showed that measured vertical loads at the toe of the facing panel can be much larger than the self-weight of the facing in mechanically stabilized earth walls. This is most likely caused by the relative movement between the backfill soil and the panels that develops panel-soil interface shear and down drag loads at the connections between the panels and the reinforcement elements.

For the tests with 4 layers of nonwoven geotextile as there was a failure with large lateral deformation, therefore the second loading steps were not considered. From Fig. 9, the different loading states (loading and reloading), reinforcement types (stiffness) and facing panel rigidity can influence the vertical soil pressure distribution. As the facing panel rigidity increases, reinforcement layers stiffness decreases, or reloading states occurs, the vertical soil pressure decreases more than the calculated values from the AASHTO method. 


\subsection{Bearing capacity of strip footing load}

Data from the load cell, the LVDTs fixed horizontally in front of the wall and over of the strip footing load were used to study the influence of the reinforcement layers on the bearing capacity of the footing and on the wall deflection.

Fig. 10 shows the footing pressure versus the footing settlement (q-dz) and the footing settlement versus wall deflection (q-dy) in reinforced backfills and with different types of reinforcement layers.

By increasing the wall face rigidity and reinforcement stiffness, the bearing capacity of strip footing increases and the wall deflection decreases. The results showed in Fig. 5 and 6 help to interpret these phenomena; for or a rigid face, a plastic area with a vertical line close to the facing panel occurred over the height of the panel, but for a flexible face, a plastic area with shallow position formed.

As shown in Fig. 10a, the ultimate bearing capacity of strip footing occurs in the model with nonwoven geotextiles at an approximate settlement of 0.08B. In addition, the effects of facing panel rigidity, reinforcement number, types and stiffness on reinforced fill were compared at this known settlement (0.08B).

The ultimate bearing capacity of a strip-footing load, based on an upper bound solution, can be written as (Sawicki and Lesniewska, 1987):

$$
P_{u}=\sigma_{0} \frac{b}{a} \tan ^{2}\left(\frac{\pi}{4}+\frac{\varphi}{2}\right)-\frac{1}{2} \gamma H
$$

where $a=$ strip footing load width, $b=$ the distance between the front wall and a farther edge of the footing, $\varphi=$ soil friction angle, $\gamma=$ the unit weight of the reinforced soil, $H=$ the height of the

wall and $\sigma_{0}=\frac{T_{u}}{S_{v}}$ that $T_{u}$ is ultimate tensile strength of the reinforcement and $S_{v}$ is the vertical space between the reinforcement layers. For the model tests with 4 layers, $H=0.8 \mathrm{~m}, b / a=1.5$ and $\sigma_{01,2,3}=50,75$ and $37.5 \mathrm{kN} / \mathrm{m}$ and $\varphi=40.5^{\circ}$, the ultimate bearing capacity from Eq. 2 will be 346 , 522 and $258 \mathrm{kPa}$ for fully flexible facing panel with geogrid, woven and nonwoven geotextiles, respectively (the overall flexural rigidity of the facing panel is not considered in this method).

Table 3 shows the comparison between the test results and this analytical method. From this table, the Sawicki and Lesniewska, (1987) method shows higher calculated values for the ultimate bearing capacity than found in the tests especially for the models with the flexible face. This difference can be because of the considered fully mobilized interaction between the soil and reinforcement layers in the analytical method. In the ultimate state of this method, only the simultaneous rupture failure mechanism was considered for reinforcement layers but from this study, only the pulling-out failure mechanism occurred. For the upper reinforcement layer as there is less overburden pressure, the pulling-out failure mechanism was noticed instead of rupture.

To consider the pulling-out failure and the facing panel flexural effect, Ahmadi and Hajialilue (2012) developed an analytical method to calculate the ultimate load-bearing capacity of a strip footing located near a reinforced soil wall. Depending on the soil, reinforcement and facing panel properties in model tests, the ultimate bearing capacities of the strip footing are shown in Table 3. There is good agreement between this method and the models with 4 layers. In models with 8 layers, the difference is more as in this method, the pulling-out condition was considered in all reinforcement layers in the failure step. 


\subsection{Maximum wall deflection}

Fig. 11a and b, show the curves of lateral wall deflection in the same footing settlement $(0.08 \mathrm{~B})$ and for the rigid and flexible models, respectively. The measurements disregard the small deflections at the end of backfill construction (set to zero). For the flexible face, the maximum lateral wall deflection occurred in $\mathrm{z} / \mathrm{H}=0.25$. For the same footing settlement $(0.08 \mathrm{~B})$, the rigid and flexible wall with woven geotextile has the smallest wall deflection.

Table 4 shows the difference between the test results and Jewell (1988) method about the maximum wall deflection under the strip footing load. In the analytical methods, the $(2 \mathrm{~V}: 1 \mathrm{H})$ distribution for the strip footing load distribution in depth was considered to calculate the maximum tensile forces on reinforcement layers. In this table, for the highly extensible reinforcement layers (nonwoven geotextile), there is a significant difference between the test results and Jewell (1988) method (almost 4-6 times).

For the stiffer reinforcement layers (geogrid and woven geotextile), the Jewell (1988) method shows better results compared to the model tests. It shows, by increasing reinforcement layers stiffness, the load distribution shape on reinforcement layers can be closer to the considered distribution in the Jewell (1988) method.

\subsection{Preloading effect on MSE walls deflection}

Tatsuoka et al. (1997) and Uchimura et al. (2003) proposed the pre-loaded and pre-stressed reinforced soil method in the abutment of geogrid. The transient and long-term residual deformations measured in the wall after pre-loading were reported to be very small. Ehrlich and Mitchell (1995) indicated that the induced stress due to soil compaction (pre-loading) may represent a kind of pre-stressing and reduce lateral displacement after wall construction.

In the model tests, after unloading the strip footing load, a second load (reloading) was applied to models, to study the effect of the preloading on the wall deflection under the strip footing load. The lateral wall deflections after applying the second loading step for the flexible and rigid walls with geogrid reinforcement are shown in Fig. 12. From this figure, the measured footing settlements in the second loading step are smaller than the first loading step, because of the preloading effect on reinforcement layers form the first loading step.

The over-consolidation effect on the lateral earth pressure (and consequently reinforcement layers tensile load) can be considered by applying the value of $F$ parameter based on Seed (1983) and Ehrlich and Mitchell (1994) formula, as:

$$
F=1-\frac{O C R R-O C R R^{\sin \varphi}}{O C R R-1}
$$

where, OCRR and $\varphi$ are the over-consolidation ratio in a retained soil structure (that is defined as the highest stress experienced divided by the current stress) and internal peak friction angle of soil, respectively.

There is good agreement between Jewell (1988) method with the test results in the second loading step by considering the preloading effect (the average value of $F$ parameter) for stiffer reinforcement layers. But still there is a significant difference between the test results and Jewell (1988) method for the models with nonwoven geotextile layers under the second loading step. 


\subsection{Nonwoven geotextile stiffness}

Yuan et al. (1998) and Wilson-Fahmy et al. (1993) from the test results showed that soil confinement had a negligible effect on the modulus for the woven geotextile and for the nonwoven geotextiles tested, the modulus increased 1.8 to 4.8 times, depending on the confining stress. Moreover, Zornberg (1994) with back analysis in the numerical modelling of full-scale test results showed that in situ nonwoven geotextile stiffness was found to vary from twice to four times the values determined from the laboratory unconfined wide width tensile tests. Palmeira (2009) has also reported the effect of confinement for nonwoven geotextiles stiffness by increasing the interlock and friction among geotextile fibres and intrusion of soil particles into geotextile voids (impregnation), which reduces the space available for fibre stretching.

PIV analysis can help to get more information about the strain distribution on the reinforcement layers location. Fig. 13 (a to h) shows the distribution of strains in 8 layers nonwoven geotextile (flexible face) and for the first loading step. From this figure, the maximum strain occurs in the second layer and the distribution is different from the Jewell (1988) method. The strain distribution is similar to the triangle shape as considered in Ahmadi and Bezuijen (2018) study and it occurs

almost in the area with the angle $\left(\frac{\pi}{4}+\frac{\varphi}{2}\right)$ under the strip footing load. As shown in Fig. 13, the maximum strain for the second layer is localized in the small part exactly under the strip footing load (because of the low stiffness of nonwoven geotextile and the texture of needle punched material, the maximum strain occurred in the small part and is not continued in the length of the reinforcement layer). By considering the triangle shape with the maximum strain value of $10 \%$ in the second layer as shown in Fig. 13b, the maximum wall deflection will be $15 \mathrm{~mm}$ and this is comparable with the measured value $(17.3 \mathrm{~mm})$. From the AASHTO (2012) method, the maximum tensile force on the second reinforcement layer is $3.4 \mathrm{kN} / \mathrm{m}$ and from the tensile test curve in

Fig. 3, the equivalent strain for this maximum tensile load will be $35 \%$. Then, the PIV analysis results on average showed 3.5 times smaller strain over the reinforcement layer than the calculated value. This can show the influence of the interaction mechanism in the stiffness of nonwoven geotextile. From Fig. 13, the measured maximum strain decreases by increasing the depth and the location of the maximum strain over the reinforcement layers moves to the wall face in the lower reinforcement layers.

Fig. 13 (a' to $\mathrm{h}^{\prime}$ ) shows, the strain distribution over the reinforcement layers in the second loading step. From this figure, the strain distribution is different from the first loading step and the maximum strain and the interacted length are smaller. For the second layer, the strain distribution located in the failure area with the angle $\left(\frac{\pi}{4}+\frac{\varphi}{2}\right)$ but with the smaller interacted length compare to the fist loading step in Fig. 13b. By integration of the strain distribution curve on the second reinforcement layer in Fig. 13b', the wall deflection will be $9.2 \mathrm{~mm}$ that is comparable with the measurement $(10.8 \mathrm{~mm})$. The last reinforcement layer $\left(8^{\text {th }}\right)$ shows a very small strain increment in the second loading step and the location of the maximum strain over the reinforcement layers in this figure moves to the wall face similar to the first loading step.

\section{COMPARASION OF MODEL RESULTS WITH THOSE OF FULL-SCALE MODELS}

The structures evaluated as part of this study correspond to reduced-scale models, with the scale factor of $1 / 5$, of the full-scale structures evaluated by Ahmadi and Bezuijen (2018). The same scale factor $(1 / 5)$ was used both for the geometry dimensions (i.e. size) of the model and the 
reinforcement stiffness. The same pressure from strip footing loads was applied on the backfill of the small-scale models as that used in the full-scale structures.

El-Emam and Bathurst (2004) and Xu et al. (2020) used a scale factor of 1/6 and 1/5 respectively to investigate the seismic performance of reduced-scale reinforced soil walls. Based on Allen and Bathurst (2019), Allen and Bathurst (2015) and Miyata et al. (2018) studies, the range of global stiffnesses for geosynthetic walls in the full-scale tests are (75-9222 $\mathrm{kPa})$. In this study and for the small-scale models with 4 and 8 reinforcement layers, the global stiffness is in the range of fullscale tests $(75-2300 \mathrm{kPa})$.

Among the different sets of small-scale models, those with 8 geogrid layers correspond to the models with a scale factor of $1 / 5$ in relation to the full-scale structures. Table 5 shows a comparison between the results obtained in the reduced-full-scale structures, including the soil parameters, reinforcement characteristics, and test results. As inferred from the results summarized in this table, the maximum wall deflections in the reduced-scale models constructed with 8 geogrid layers in the first loading step are 10.3 and $11 \mathrm{~mm}$ for a surcharge load of $300 \mathrm{kPa}$ in the rigid and flexible walls, respectively. Evaluation of the results indicates that the displacement values of the small and fullscale models compare particularly well before the preloading that was conducted in the full-scale models. However, the difference between the displacement values of scaled and full-scale models are significant (4.6 to 4.9 times in rigid and flexible walls) for the second loading step (that is close to the scale factor of $1 / 5$ in small-scale models).

A preloading effect from roller compactor (Dynapac CA302) as a localized load was observed in the full-scale structures before applying $300 \mathrm{kPa}$ static strip footing load. Based on Seed and Duncan (1983) and Duncan and Seed (1986), the loading imposed by a typical vibratory roller can be modelled by applying a static load that is approximately two to four times the weight of the roller. In fact, when considering a static vertical stress equivalent to 4 times that of the roller compactor (432 kPa per unit width of the reinforced wall), a good comparison could be obtained between the results in the full-scale structure and those in the second loading step in small-scale tests (that can show the preloading effect in both models).

Finally, by mobilization of the reinforcement layers under the preloading mechanism from the dynamic or static loads, the maximum lateral wall deflection will decrease both in full-scale and small-scale models. This mobilization can be done by a preloading effect of a dynamic roller compactor or by a static load in the same position.

While important insight can be gained from $1 \mathrm{~g}$ models regarding mechanisms involved in new approaches such as the preloading of MSE, it is important to also highlight the limitations of reduced-scale models in reproducing the overall behaviour of full-scale prototype structures. In particular, the impact of stress dependency on the soil properties cannot be reproduced in the reduced-scale model for the case of stresses induced by the self-weight of a geotechnical structure. In this particular study, such deficiency was addressed, at least partly, because the magnitude of the surcharge-induced stresses dominates the overall state of stresses within the reinforced soil mass. Specifically, the stresses in the model are induced by comparatively large strip footing loads. Nonetheless, stresses in the geosynthetics located comparatively from the footing in the reducedscale models may be reasonably different than those in a full-scale prototype. However, the focus of this study is on gaining insight on preloading as an advantageous methodology, such insight will add to our current knowledge base on this topic, particularly since footing pressures in this study are the same in the small-scale model as in the prototype. 


\section{CONCLUSIONS}

This paper presents a series of instrumented scaled models by considering the influence of facing panel rigidity, stiffness of the reinforcement layers and preloading on the lateral wall deflection, strip footing settlement, vertical earth pressure and consequently, the maximum tensile force in the reinforcement layers. Furthermore, the measurements are compared with the results of analytical methods about the bearing capacity of strip footing load and maximum wall deflection. PIV analysis results in this study, provided measurements of failure zones inside the soil, before and after applying the strip footing load that illustrate the effect of facing panel rigidity, stiffness of the reinforcement layers and preloading on the related system behaviour.

As mentioned before, preloading is induced by the strip footing load, which increases the soil density and horizontal stresses. A consequence of the increment in horizontal stresses is the elongation of the reinforcement layers. After unloading the strip footing, the tensile force in the reinforcement layer in the elastic range will result in an added confinement within the soil. The induced tensile force from the first loading can partly result in soil upward movements but the primary effect is a pre-stressed force. On the other hand, the fist loading step can activate the reinforcement layers within the soil mass by decreasing the displacements needed to mobilize the maximum frictional and bearing resistance in the longitudinal and transverse ribs.

Then, in a new approach to study the deformation of MSE walls, a preloading is applied to simulate the densification of the soil layers. This densification will activate the reinforcement layers inside the soil and decrease the large necessary displacement for mobilization of the ultimate bearing and friction resistance. A localized static or dynamic surcharge load close to the facing panel can be used as a preloading to mobilize the reinforcement layers inside the soil and prestresses them. Due to this prestressing, the wall deflection and strip footing settlement under the future surcharge loads will be less than without considering this pre-stressing condition (depending on the magnitude of the first applied load).

- The vertical soil pressure in loading and reloading steps was found to decrease more than predicted by typical design methods for increasing facing rigidity and decreasing reinforcement stiffness.

- The total maximum wall deflection induced during the second loading was almost half the value reached during the first loading. In addition, the footing settlement induced during the second loading was also smaller than that obtained during the first loading.

- Evaluation of the results indicates that the displacement values of the small and full-scale models compare particularly well after the preloading that was conducted in the full-scale models. The measured maximum wall deflection in small-scale models and in the second loading step has the scale factor of 1/5 compared to the full-scale models.

- Increasing wall face rigidity and reinforcement stiffness was found to lead to decrease lateral wall deflections and footing settlements. On the other hand, the bearing capacity of strip footing increases by increasing the wall face rigidity and reinforcement stiffness.

- The models constructed with a comparatively rigid facing resulted in failure zones that initiated at a lower elevation on the facing than for the case of models with a more flexible facing. That is, application of strip footing loads led to a deeper failure zone when using rigid facing than in the case of flexible facing.

- In the rigid wall compare to the flexible wall, there is a clear shear zone generated close to wall face in the vertical direction (soil-wall face frictional interaction). 
- The results from PIV analysis revealed that two failure lines with the angle $\left(\frac{\pi}{4}+\frac{\varphi}{2}\right)$ formed under the strip footing load in the loading and reloading steps. Specifically, a surface developed from the inner edge of the strip footing and with a tendency to the wall face (shallow position) while a second one developed from the outer edge of the strip footing (deep position).

- PIV analysis results showed that the strain distribution presents a triangular shape on the models with rigid and flexible faces for non-woven geotextile and under the strip footing load.

- For the reinforcement layers with only frictional interaction (nonwoven and woven geotextiles), the failure zones are deeper than the layers with bearing and frictional resistance (geogrid). As in geogrid layers more displacement is needed to get the maximum bearing resistance of the transverse ribs.

- Good agreement between analytical predictions and experimental results were obtained in the loading and reloading step.

- The maximum strain value from PIV analysis and for the nonwoven geotextile is smaller than the value obtained through (AASHTO (2012) method, reflecting the influence of the confinement on the stiffness of this type of reinforcement.

- Compared to AASHTO (2012) and FHWA (2009), the failure zone defined using PIV analysis is shown to reach the wall face at a location above the toe of the wall, which is adopted in those guidelines. This may have implications not only on the locus of the maximum tension in the reinforcements but also in the magnitude of such maximum tension.

- By considering the preloading effect, the necessary stiffness of the reinforcement layers designed for the surcharge loads can be decreased, because the preloading leads to a stiffer behaviour. It means, a single loading-unloading cycle with the same magnitude of the future surcharges, may have the same effect on the wall deflection and footing settlement by using two times stiffer reinforcement layers.

- The results show that the maximum wall deflection for the flexible facing panel and under the first and second loading of strip footing load occurred in $\mathrm{z} / \mathrm{H}=0.25$ which is in good agreement with the full-scale tests of Abu-Hejleh et al. (2002) and Ahmadi and Bezuijen (2018). 


\section{ACKNOWLEDGEMENT}

The authors appreciate the help of the Iranian Ministry of Science, Research and Technology and CWO (Ghent University funding) for financial support.

\section{REFERENCES}

AASHTO. (2012). LRFD Bridge Design Specifications, sixth ed. American Association of State Highway and Transportation Officials, Washington, D.C., USA.

Abu-Hejleh, N., Zornberg, J.G., Wang, T. \& Watcharamonthein, J. (2002). Monitored displacements of unique geosynthetic-reinforced soil bridge abutments. Geosynthetics International, 9(1): 71-95.

Adams, M. (1997). Performance of a prestrained geosynthetic reinforced soil bridge pier. Mechanically stabilized backfill, Balkema, Rotterdam, Netherlands, pp. 35-53.

Adams, M., Nicks, J., Stabile, T., Wu, J., Schlatter, W. \& Hartmann, J. (2011). Geosynthetic reinforced soil integrated bridge system interim implementation guide. FHWA-HRT-11-026, U.S. Dept. of Transportation, Washington, DC.

Ahmadi, H. (2020). Geosynthetic-reinforced soil retaining walls subjected to surcharge loads. Ph.D. dissertation, Ghent University, Ghent, 180 p.

Ahmadi, H. \& Hajialilue-Bonab, M. (2012). Experimental and analytical investigations on bearing capacity of strip footing in reinforced sand backfills and flexible retaining wall. Acta Geotechnica, 7(4): 357-373.

Ahmadi, H. \& Bezuijen, A. (2018). Full-scale mechanically stabilized earth (MSE) walls under strip footing load. Geotextiles and Geomembranes, 46(3): 297-311.

Allen, T.M. \& Bathurst, R.J. (2015). An improved simplified method for prediction of loads in reinforced soil walls. ASCE J. Geotech. Geoenvironmental Eng, 141 (11), 04015049.

Allen, T.M. \& Bathurst, R.J. (2019). Geosynthetic reinforcement stiffness characterization for MSE wall design. Geosynthetics International, 25(6): 592-610.

Bathurst, R.J. (2020). Developments in MSE Wall Research and Design. In: Tatsouka F., Guler E., Shehata H., Giroud J. (eds) Innovative Infrastructure Solutions using Geosynthetics, GeoMEast 2019, Sustainable Civil Infrastructures. Springer, Cham, pp. 22-50.

Berg, R. R., Christopher, B. R. \& Samtani, N. C. (2009). Design of mechanically stabilized earth walls and reinforced slopes. Rep. No. FHWA-NHI-10-024 Vol. I and NHI-10-025 Vol. II, Federal Highway Administration, 306 Vol. 1 and 378 Vol. 2, Washington, DC.

Bourgeois, E., Soyez, L. \& Le Kouby, A. (2011). Experimental and numerical study of the behaviour of a reinforced-earth wall subjected to a local load. Computers and Geotechnics, 38(4): 515-525.

Brabant, K. (2001). Mechanically Stabilized Earth Walls for Support of Highway Bridges. The Reinforced Earth Company. Unpublished Report.

Coulomb, C.A. (1776). Essai sur une application des regles de maximis et minimis a quelqes problemas de stratique relatifs a l'architecture. Memoires de mathematique et de physique. pp. 343-382 Presentes a l'Academie Royale des Sciences, Paris 7. 
Damians, I.P., Bathurst, R.J., Josa, A. \& Lloret, A. (2014). Numerical study of the influence of foundation compressibility and reinforcement stiffness on the behavior of reinforced soil walls. International Journal of Geotechnical Engineering, 8(3): 247-59.

Duncan, J.M. \& Seed, R.B. (1986). Compaction-induced earth pressures under K0-conditions. Journal of Geotechnical Engineering, 112 (1): 1-22.

Ehrlich, M. \& Mitchell, J.K. (1994). Working stress design method for reinforced soil walls. Journal of Geotechnical Engineering, 120 (4): 625-645.

Ehrlich, M. \& Mitchell, J.K. (1995). Working stress design method for reinforced soil walls. Closure. Journal of Geotechnical Engineering, 121 (11): 820-821.

El-Emam, M. \& Bathurst, R.J. (2004). Experimental design, instrumentation and interpretation of reinforced soil wall response using a shaking table. International Journal of Physical Modelling in Geotechnics, 4(4): 13-32.

Gotteland, P., Gourc, J.P. \& Villard, P. (1997). Geosynthetic reinforced structures as bridge abutments: Full scale experimentation and comparison with modelisations. Mechanically stabilized backfill, Balkema, Rotterdam, Netherlands, pp. 25-34.

Ho, S.K. \& Rowe, R.K. (1996). Effect of wall geometry on the behavior of reinforced soil walls. Geotextiles and Geomembranes, 14(10): 521-541.

Jewell, R.A. (1988). Reinforced soil wall analysis and behavior. The application of polymeric reinforcement in soil retaining structures, Springer, Dordrecht, Netherlands, pp. 365-408.

Ketchart, K. \& Wu, J.T.H. (1997). Performance of geosynthetic-reinforced soil bridge pier and abutment. Denver, Colorado, USA, Special Presentation, International Symposium on Mechanically Stabilized Backfill, A. A. Balkema Publishers, The Netherlands, pp. 101-116.

Lackner, C., Bergado, D.T. \& Semprich, S. (2013). Prestressed reinforced soil by geosyntheticsconcept and experimental investigations. Geotextiles and Geomembranes, 37, 109-123.

Lee, K.Z.Z. \& Wu, J.T.H. (2004). A synthesis of case histories on GRS bridge-supporting structures with flexible facing. Geotextiles and Geomembranes, 22(4): 181-204.

Lesniewska, D. \& Wood, D.M. (2009). Observations of stresses and strains in a granular material. Journal of Engineering Mechanics, pp. 135(9).

Miyata, Y., Bathurst, R.J. \& Allen, T.M. (2018). Evaluation of tensile load model accuracy for PET strap MSE walls. Geosynthetics International, 25(6): 656-671.

Xu, P., Hatami, K. \& Jiang, G. (2020). Shaking table study of the influence of facing on reinforced soil wall connection loads. Geosynthetics International, 1-51.

Palmeira, E.M. (2009). Soil-geosynthetic interaction: Modeling and analysis. Geotextiles and Geomembranes, 27(5): 368-390.

Plumey, S., Muttoni, A., Vulliet, L. \& Labiouse, V. (2011). Analytical and numerical analyses of the load-bearing capacity of retaining walls laterally supported at both ends. International Journal for Numerical and Analytical Methods in Geomechanics, 35(9): 1019-1033.

Rowe, R.K. \& Ho, S.K. (1997). Continuous Panel Reinforced Soil Walls on Rigid Foundations. Journal of Geotechnical and Geoenvironmental Engineering, 123(10): 912-920.

Rowe, R.K. \& Ho, S.K. (1998). Horizontal deformation in reinforced soil walls. Canadian Geotechnical Journal, 35(2): 312-327.

Ruiken, A., Ziegler, M., Vollmert, L. \& Duzic, I. (2010). Recent findings about the confining effects of geogrids from large scale laboratory testing. 9th International Conference on Geosynthetics, Brazil.

Sawicki, A. \& Lesniewska, D. (1987). Failure modes and bearing capacity of reinforced soil retaining walls. Geotextiles and Geomembranes, 5 (1): 29-44. 
Schlosser, F. \& Bastick, M. (1991). Reinforced Earth. In: Foundation Engineering Handbook, 2nd edition. Editor: H.-Y. Fang. Chapman \& Hall, New York, pp. 778-795.

Seed, R.M. (1983). Compaction-induced Stresses and Deflections on Earth Structure. PhD. thesis. University of California, Berkeley, CA, 447 p.

Teixeira, S.H.C., Benedito, S.B. \& Zornberg, J.G. (2007). Pull-out resistance of individual longitudinal and transverse geogrid ribs. Journal of Geotechnical and Geo-Environmental Engineering ASCE January, 37-50.

Tatsuoka, F. (1992). Roles of facing rigidity in soil reinforcing, Keynote Lecture, Proc. Earth Reinforcement Practice (IS-Kyushu '92), (1), pp. 831-870.

Tatsuoka, F., Uchimura, T. \& Tateyama, M. (1997). Preloaded and pre-stressed reinforced soil. Soils and Foundations, 37 (3): 79-94.

Uchimura, T., Tateyama, M., Tanaka, I. \& Tatsuoka, F. (2003). Performance of a preloadedprestressed geogrid-reinforced soil pier for a railway bridge. Soils and Foundations, 43 (6): 155-171.

White, D.J., Take, W.A. \& Bolton, M.D. (2001). Measuring soil deformation in geotechnical models using digital images and PIV analysis. Proceedings of 10th international conference on computer methods and advances in geomechanics, Tucson, Arizona, pub., Balkema, Rotterdam, pp. 997-1002.

White, D.J., Take, W.A. \& Bolton, M.D. (2003). Soil deformation measurement using particle image velocimetry (PIV) and photogrammetry. Geotechnique, 53(7): 619-631.

White, D.J., Randolph, M. \& Thompson, B. (2005). An image-based deformation measurement system for the geotechnical centrifuge. International Journal of Physical Modelling in Geotechnics, 5(3): 1-12.

Wilson-Fahmy, R.F., Koerner, R. M. \& Fleck, J. A. (1993). Unconfined and confined width tension testing of geosynthetics," Geosynthetic Soil Reinforcement Testing Procedures, ASTM STP 1190.

Wu, J. T. H., Ketchart, K. \& Adams, M. (2001). GRS bridge piers and abutments. Rep. No. FHWARD-00-038, U.S. Dept. of Transportation, Washington, DC.

Xiao, C., Han, J. \& Zhang, Z. (2016). Experimental study on performance of geosyntheticreinforced soil model walls subjected to static footing loading. Geotextiles and Geomembranes, 44(1): 81-94.

Yuan, Z., Swan, R. H., Jr. \& Bachus, R.C. (1998). Soil confinement effect on stress-strain properties of geosynthetics, Proceedings of the Sixth International Conference on Geosynthetics, Atlanta, GA, pp. 523-528.

Zornberg, J.G. (1994). Performance of geotextile-reinforced soil structures. Ph.D. dissertation, University of California, Berkeley, 504 p.

Zornberg, J.G., Morsy, A.M., Mofarraj, B., Christopher, B.R., Leshchinsky, D., Han, J., Tanyu, B.F., Gebremariam, F.T., Shen, P. \& Jiang, Y. (2019). Proposed Refinements to Design Procedures for Geosynthetic Reinforced Soil (GRS) Structures in AASHTO LRFD Bridge Design Specifications. National Cooperative Highway Research Program (NCHRP), Project 24-41, Transportation Research Board, Washington DC, March, 64 p. 


\section{APPENDIX A. PROCEDURE OF THE ANALYTICAL METHOD BY AHMADI AND HAJIALILUE-BONAB (2012) FOR CALCULATING THE ULTIMATE LOAD-BEARING CAPACITY UNDER STRIP FOOTING LOCATED NEAR THE REINFORCED SOIL WALLS.}

By considering the facing panel rigidity, Ahmadi and Hajialilue (2012) developed an analytical method for calculating the ultimate load-bearing capacity under strip footing load located near the reinforced soil walls. In this model the ultimate strip footing load $\left(q_{r}\right)$ can be described as:

$$
q_{r}=\frac{1}{\bar{W}_{q}} \cdot\left(\frac{(1+\xi) M_{R}}{x \tan \theta_{f}\left(\xi-\xi^{2}\right)}+\sum_{i=1}^{n} T_{p} \cdot L_{i}-\bar{W}_{\gamma}\right)
$$

Where $L_{i}$ (the perpendicular depth of $i_{t h}$ reinforcement layer) is measured downwards from the center of rotation $(\mathrm{O}) ; T_{p}$ is the pull-out resistance force of the $i_{t h}$ layer; $n$ is the number of the reinforcement layers.

$$
\begin{aligned}
& \bar{W}_{q}=\int_{\theta_{0}}^{\theta_{f}} \frac{x}{\left(\tan \theta_{f}-\tan \theta_{0}\right)} \cdot \frac{\left(\tan \theta_{f}-\tan \theta\right) \cdot(\tan \theta-\tan \phi)}{\sin \theta \cdot \cos \theta} \cdot e^{-2 \theta \cdot \tan \phi} \cdot d \theta \\
& \bar{W}_{\gamma}=\int_{\theta_{0}}^{\theta_{f}} \frac{x^{2} \cdot \gamma}{\left(\tan \theta_{f}-\tan \theta_{0}\right)} \cdot \frac{\left(\tan \theta_{f}-\tan \theta\right) \cdot(\tan \theta-\tan \phi)}{\cos ^{2} \theta} \cdot(3 \tan \phi \cdot \cos \theta+\sin \theta- \\
& \left.3 \tan \phi \cdot e^{-3 \theta \cdot \tan \phi}\right) \cdot d \theta \\
& \quad \cos \theta_{0}=e^{-\theta_{0} \cdot \tan \phi}
\end{aligned}
$$

Other parameters are shown in Fig.A1 and more details are provided by Ahmadi and Hajialilue (2012).

Assuming a friction coefficient between the reinforcement and the soil defined by $\mu$, the pull-out force resistance can be calculated as:

$$
T_{p}=2 \cdot l_{e} \cdot \gamma \cdot z \cdot \mu
$$

By considering the soil and facing panel properties from the small-scale tests with 4 layers of geogrid, the parameters in this method will be; $\mathrm{x}=0.059, \theta_{0}=1.19(\mathrm{rad})$ and $\theta_{f}=1.48(\mathrm{rad})$, then the ultimate bearing capacity of strip footing for 4 layers of geogrid when $M_{r}=0$ (without facing resistance) is $228 \mathrm{kPa}$. For the plywood, the maximum bending resistance is considered from:

$$
M_{r}=\sigma_{y} \times S
$$

where, $\sigma_{y}$ is tensile strength and $S=b h^{2} / 6$, is the moment inertia of the section with width $(b)$ and height $(h)$. For plywood, $\sigma_{y}=31 \mathrm{MPa}, S=1.2 \times 10^{-6} \mathrm{~m}^{3}$, then $M_{r}$ will be $0.037 \mathrm{kN} . \mathrm{m}$. Then the ultimate bearing capacity of strip footing load based on this method for 4 layers of geogrid when $\mu=1$ and $\xi=0.31$ (from PIV result) and for the flexible wall will be $245 \mathrm{kPa}$.

As the rigid face has a reasonably high bending capacity to be also overcome by the strip footing load, the maximum amount for $M_{r}$ can be calculated from $q_{r}$, Formula based on the assumption that with this $M_{r}$, the top reinforcement layer would fail by pull out. Accordingly, $M_{r}=1.51 \mathrm{kN} . \mathrm{m}$ and the ultimate bearing capacity for strip footing for 4 layers of geogrid will be $301.08 \mathrm{kPa}$ for the rigid face. 

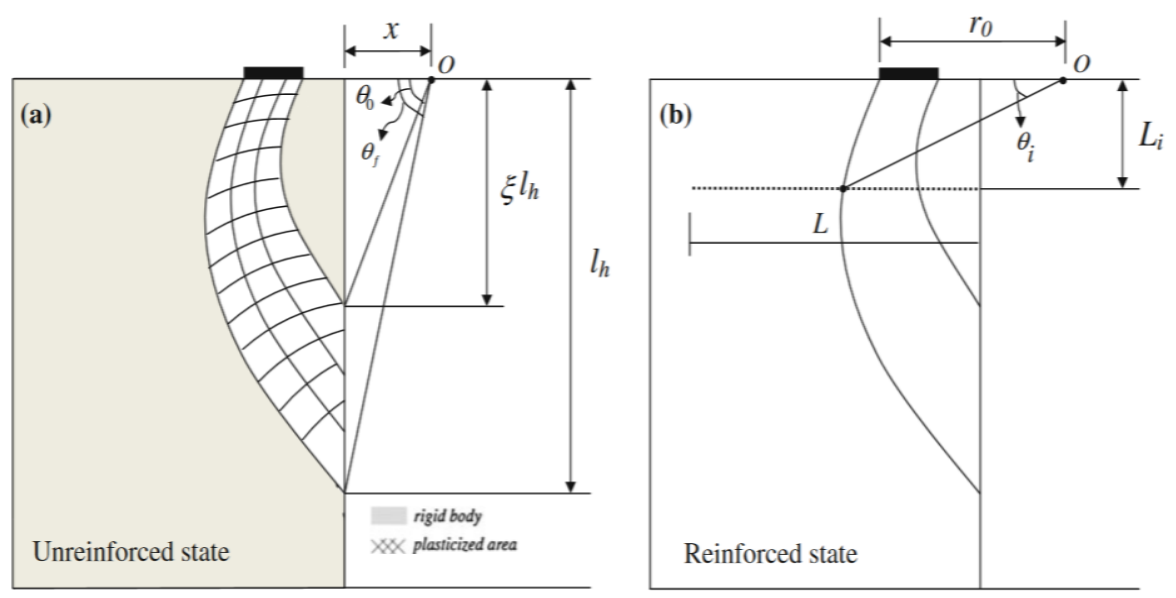

Fig. A1. Failure mechanism and parameters for analytical analysis, (Ahmadi and Hajialilue-Bonab, 2012).

Table 1: Soil and reinforcement parameters in scaled tests.

\begin{tabular}{lcc}
\hline Parameter & Symbol & Value \\
\hline Unit weight-soil $\left(\mathrm{kN} / \mathrm{m}^{3}\right)$ & $\gamma_{\mathrm{s}}$ & 15.72 \\
Coefficient of uniformity & $\mathrm{C}_{\mathrm{u}}$ & 1.32 \\
Coefficient of curvature & $\mathrm{C}_{\mathrm{c}}$ & 0.96 \\
Peak soil friction angle from the direct shear test $\left(^{\circ}\right)$ & $\varphi_{d}$ & 40.5 \\
Residual friction angle from the direct shear test $\left(^{(}\right)$ & $\varphi_{r}$ & 31.15 \\
Estimated soil plain strain friction angle $($ Bolton 1986$)\left({ }^{\circ}\right)$ & $\varphi_{p}$ & 46 \\
Cohesion-soil $(\mathrm{kPa})$ & $\mathrm{C}$ & 0 \\
Reinforcement length $(\mathrm{m})$ & $\mathrm{L}$ & 0.6 \\
Vertical spacing of reinforcement in 4 layers $(\mathrm{m})$ & $\mathrm{S}_{\mathrm{v}}$ & 0.1 and 0.2 \\
Vertical spacing of reinforcement in 8 layers $(\mathrm{m})$ & $\mathrm{S}_{\mathrm{v}}$ & 0.05 and 0.1 \\
Short term stiffness of geogrid $(\varepsilon \leq 4 \%)(\mathrm{kN} / \mathrm{m})$, & $\mathrm{E}_{1} \mathrm{~A}$ & 150 \\
Ultimate tensile strength $(\mathrm{kN} / \mathrm{m})$ & $\mathrm{T}_{\mathrm{u} 1}$ & 10 \\
Short term stiffness of woven geotextile $(\varepsilon \leq 4 \%)(\mathrm{kN} / \mathrm{m})$ & $\mathrm{E}_{2} \mathrm{~A}$ & 230 \\
Ultimate tensile strength $(\mathrm{kN} / \mathrm{m})$ & $\mathrm{T}_{\mathrm{u} 2}$ & 25 \\
Short term stiffness of nonwoven geotextile $(\varepsilon \leq 40 \%)(\mathrm{kN} / \mathrm{m})$ & $\mathrm{E}_{3} \mathrm{~A}$ & 15 \\
Ultimate tensile strength $(\mathrm{kN} / \mathrm{m})$ & $\mathrm{T}_{\mathrm{u} 3}$ & 8 \\
\hline
\end{tabular}


Table 2: Laboratory model test conditions.

\begin{tabular}{lccccc}
\hline Test & $\mathrm{N}$ & $\mathrm{u} / \mathrm{B}$ & $\mathrm{h} / \mathrm{H}$ & $\mathrm{b} / \mathrm{B}$ & $\mathrm{L} / \mathrm{H}$ \\
\hline $\begin{array}{l}\text { 4 layers-nonwoven-F-1 } \\
\text { 4 layers-nonwoven-R-1 }\end{array}$ & 4 & 0.25 & 0.25 & 0.5 & 0.75 \\
$\begin{array}{l}\text { 4 layers-woven-F-1,2 } \\
\text { 4 layers-woven-R-1,2 }\end{array}$ & 4 & 0.25 & 0.25 & 0.5 & 0.75 \\
$\begin{array}{l}\text { 4 layers-geogrid-F-1,2 } \\
\text { 4 layers-geogrid-R-1,2 }\end{array}$ & 4 & 0.25 & 0.25 & 0.5 & 0.75 \\
$\begin{array}{l}\text { 8 layers-nonwoven-F-1 } \\
\text { 8 layers-nonwoven-R-1,2 }\end{array}$ & 8 & 0.5 & 0.125 & 0.5 & 0.75 \\
$\begin{array}{l}\text { 8 layers-woven-F-1,2 } \\
\text { 8 layers-woven-R-1,2 }\end{array}$ & 8 & 0.5 & 0.125 & 0.5 & 0.75 \\
\hline
\end{tabular}

Table 3: The ultimate bearing capacity of the strip footing load for flexible (F) and rigid (R) facing.

\begin{tabular}{lcccc}
\hline \multicolumn{1}{c}{ Test } & $\mathrm{N}$ & $\begin{array}{c}\text { Tests } \\
\left(\mathrm{kN} / \mathrm{m}^{2}\right)\end{array}$ & $\begin{array}{c}\text { Sawicki and } \\
\text { Lesniewska }(1987) \\
\left(\mathrm{kN} / \mathrm{m}^{2}\right)\end{array}$ & $\begin{array}{c}\text { Ahmadi and Hajialilue } \\
(2012) \\
\left(\mathrm{kN} / \mathrm{m}^{2}\right)\end{array}$ \\
\hline 4layers-nonwoven-F/R & 4 & $120 / 204$ & $258 / 258$ & $173 / 212$ \\
4layers-woven-F/R & 4 & $306 / 390$ & $522 / 522$ & $339 / 415$ \\
4layers-geogrid-F/R & 4 & $277 / 375$ & $346 / 346$ & $245 / 301$ \\
8layers-nonwoven-F/R & 8 & $278 / 386$ & $522 / 522$ & $426 / 522$ \\
8layers-woven-F/R & 8 & $503 / 506$ & $1051 / 1051$ & $583 / 714$ \\
8layers-geogrid-F/R & 8 & $460 / 504$ & $698 / 698$ & $545 / 668$ \\
\hline
\end{tabular}


Table 4: Maximum wall deflection for the first loading and second loading steps at the ultimate load stage

\begin{tabular}{lcccc}
\multicolumn{5}{c}{$(\mathrm{dz}=0.08 \mathrm{~B}$ and $0.04 \mathrm{~B})}$. \\
\hline Test & $\mathrm{N}$ & $\begin{array}{c}\text { Tests } \\
(\mathrm{mm})\end{array}$ & $\begin{array}{c}\text { Jewell (1988) } \\
\text { method }\end{array}$ & $\begin{array}{c}\text { Jewell (1988) } \\
\text { modified method }\end{array}$ \\
\hline 4 layers-nonwoven-F-1/R-1 & 4 & $16.5 / 20.3$ & $60.1 / 100$ & $-/-$ \\
4 layers-woven-F-1/R-1 & & $11.8 / 15.5$ & $10.9 / 13.7$ & $-/-$ \\
4 layers-woven-F-2/R-2 & 4 & $5.5 / 7.1$ & $-/-$ & $4.1 / 5.2$ \\
4 layers-geogrid-F-1/R-1 & 4 & $13 / 17$ & $13.2 / 18.2$ & $-/-$ \\
4 layers-geogrid-F-2/R-2 & & $6.1 / 8.5$ & $-/-$ & $5.1 / 7.2$ \\
8 layers-nonwoven-F-1/R-1 & 8 & $17.3 / 22.1$ & $101 / 140.3$ & $-/-$ \\
8 layers-nonwoven-F-2/R-2 & 8 & $7.8 / 10.8$ & $-/-$ & $33.8 / 46.8$ \\
8 layers-woven-F-1/R-1 & & $12.2 / 11.6$ & $12.9 / 13.7$ & $-/-$ \\
8 layers-woven-F-2/R-2 & & $5.5 / 4.6$ & $-/-$ & $4.7 / 4.4$ \\
8 layers-geogrid-F-1/R-1 & & $14.9 / 16.1$ & $16.7 / 18.3$ & $-/-$ \\
8 layers-geogrid-F-2/R-2 & 8 & $7.2 / 7.8$ & $-/-$ & $6.2 / 6.7$ \\
\hline
\end{tabular}

Table 5: Soil and reinforcement parameters in full and small-scale tests.

\begin{tabular}{|c|c|c|}
\hline Parameter & Full-scale test & Small-scale test \\
\hline Unit weight-soil $\left(\mathrm{kN} / \mathrm{m}^{3}\right)$ & 17.3 & 15.7 \\
\hline Peak soil friction angle from the triaxial test $\left(^{\circ}\right)$ & 39.09 & 40.5 \\
\hline Residual friction angle from the triaxial test $\left(^{\circ}\right)$ & 35.1 & 31.3 \\
\hline Soil dilation angle from the test $\left({ }^{\circ}\right)$ & 12.5 & 11.7 \\
\hline Cohesion-soil (kPa) & 0 & 0 \\
\hline Reinforcement length (m) & 3 & 0.6 \\
\hline Height of the wall (m) & 4 & 0.8 \\
\hline Vertical spacing of reinforcement $(\mathrm{m})$ & 0.25 and 0.50 & 0.05 and 0.1 \\
\hline $\begin{array}{l}\text { Long term (1000 hour) stiffness of reinforcements }(\varepsilon \leq 0.5 \%) \\
(\mathrm{kN} / \mathrm{m})\end{array}$ & 670 & 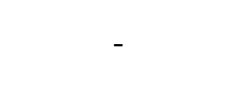 \\
\hline Short-term (1 hour) stiffness of reinforcements (kN/m) & 700 & 150 \\
\hline Strip footing load $\left(\mathrm{kN} / \mathrm{m}^{2}\right)$ & Up to 300 & Up to 500 \\
\hline Width of the strip footing load (m) & 1 & 0.2 \\
\hline $\begin{array}{l}\text { Rigid wall deflection under the } 300 \mathrm{kPa} \text { load }(\mathrm{mm}) \text { - first } \\
\text { loading step in small-scale test }\end{array}$ & 12.1 & 10.3 \\
\hline $\begin{array}{l}\text { Flexible wall deflection under the } 300 \mathrm{kPa} \text { load }(\mathrm{mm}) \text { - first } \\
\text { loading step in small-scale test }\end{array}$ & 16.2 & 11 \\
\hline $\begin{array}{l}\text { Rigid wall deflection under the } 300 \mathrm{kPa} \text { load }(\mathrm{mm}) \text { - second } \\
\text { loading step (after unloading } 500 \mathrm{kPa} \text { ) }\end{array}$ & - & 2.6 \\
\hline $\begin{array}{l}\text { Flexible wall deflection under the } 300 \mathrm{kPa} \text { load }(\mathrm{mm}) \text { - second } \\
\text { loading step (after unloading } 460 \mathrm{kPa} \text { ) }\end{array}$ & - & 3.3 \\
\hline
\end{tabular}




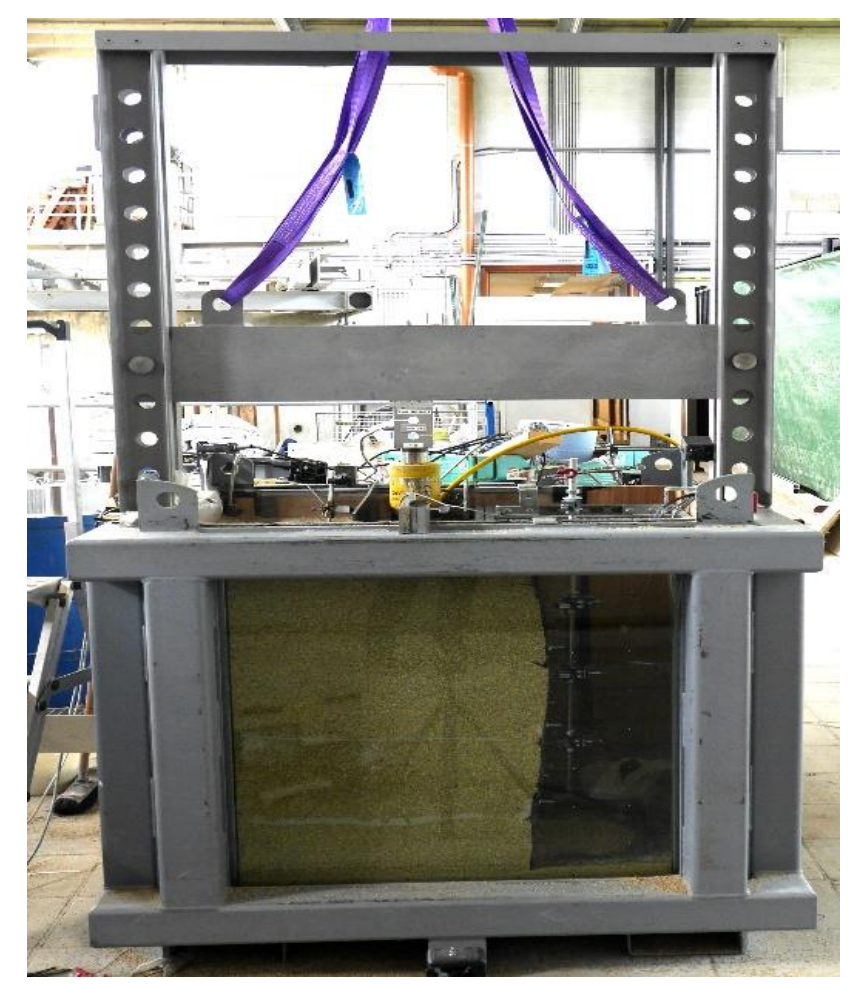

a)

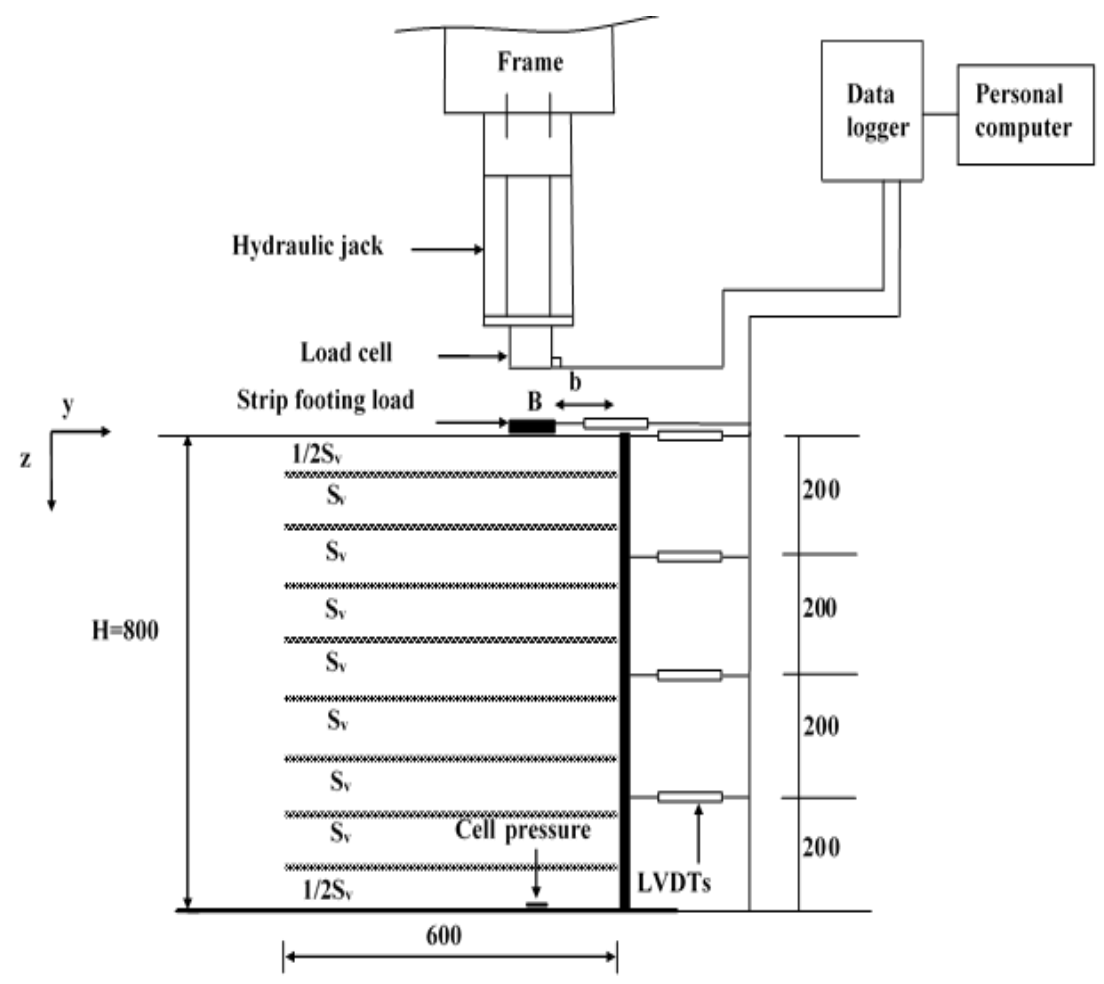

b)

Fig. 1. Test layout for reinforced soil wall and parameter symbols (dimensions in mm). 


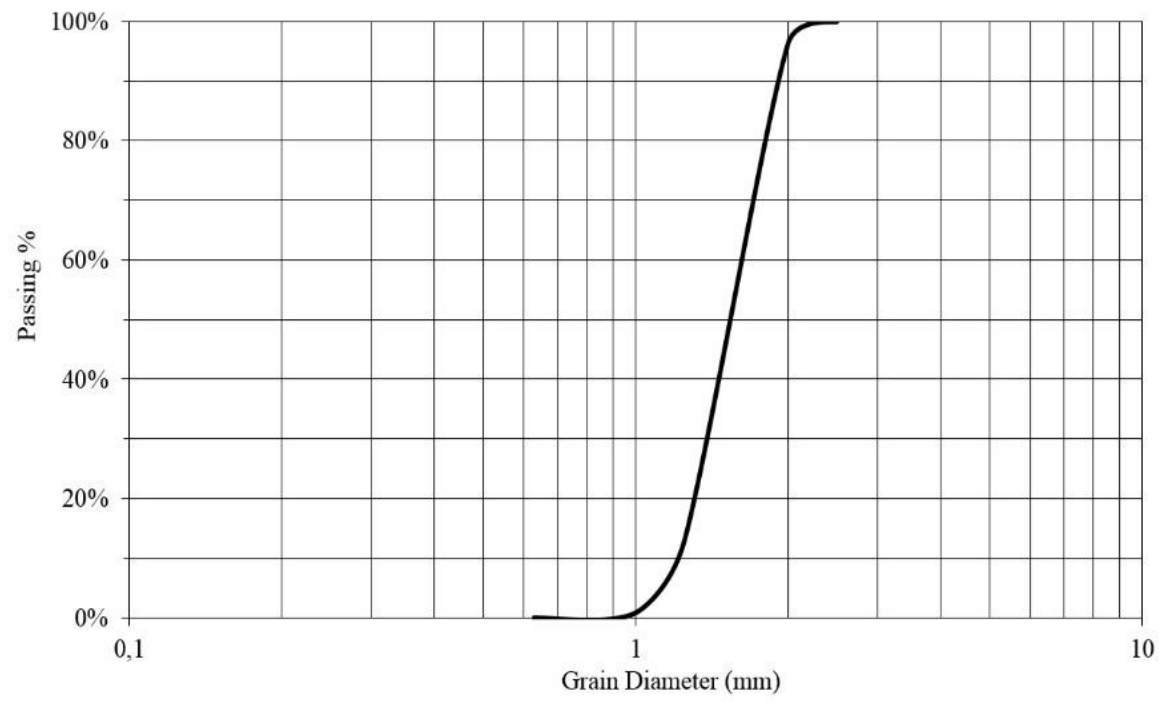

Fig. 2. Grain size distribution of the sand used in this investigation.

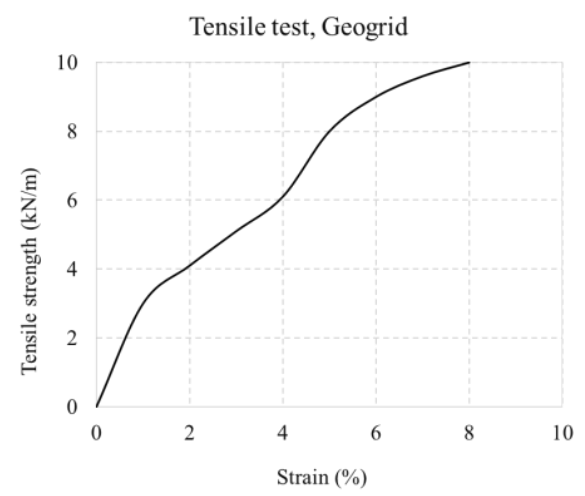

a)

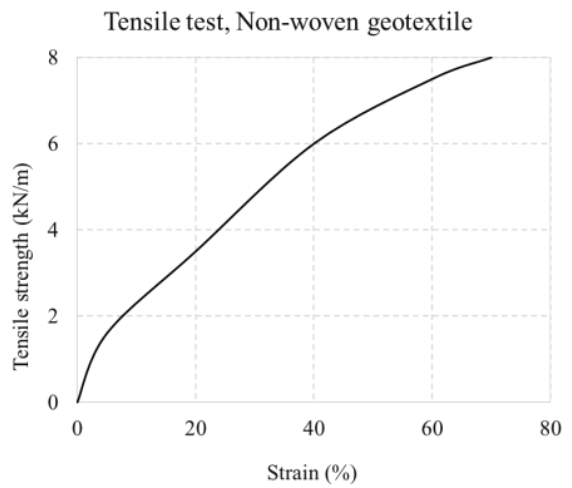

c)

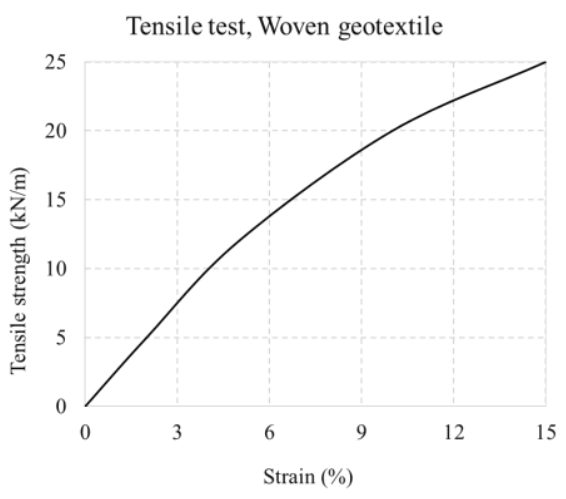

b)

Fig. 3. Tensile load test results until the maximum value; a) geogrid, b) woven geotextile and c) non-woven geotextile. 
a)

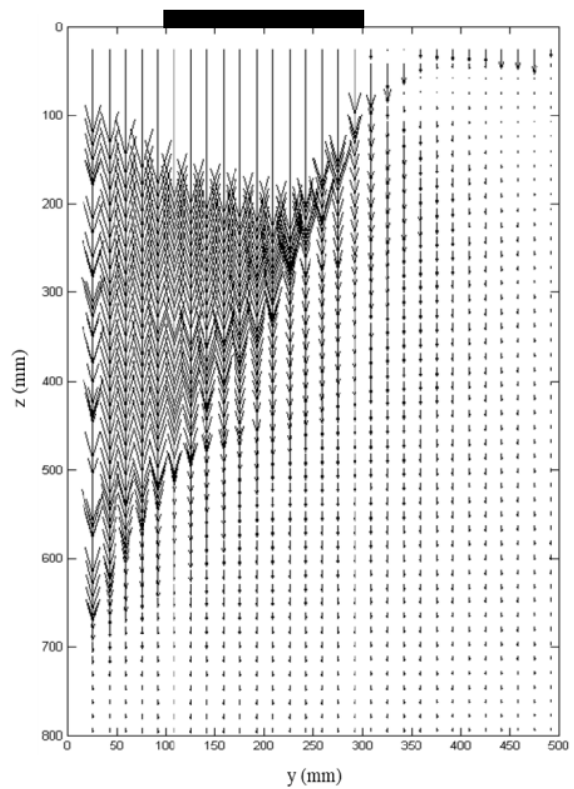

b)

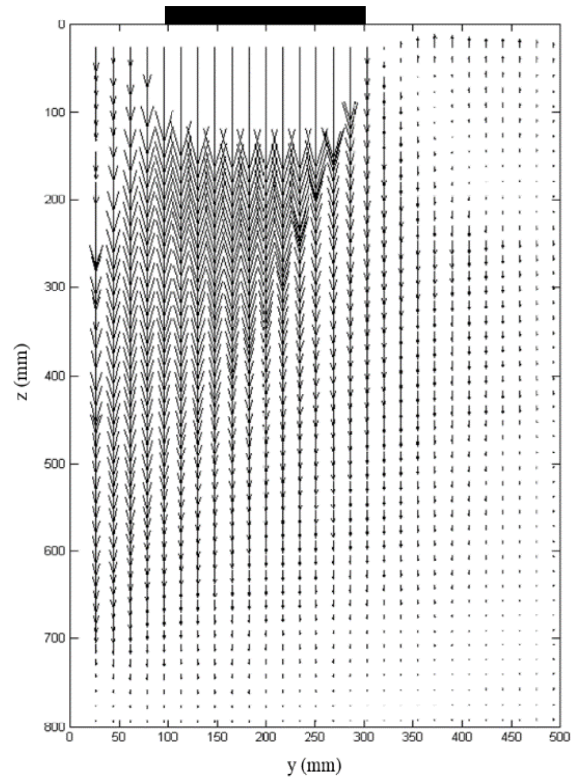

c)

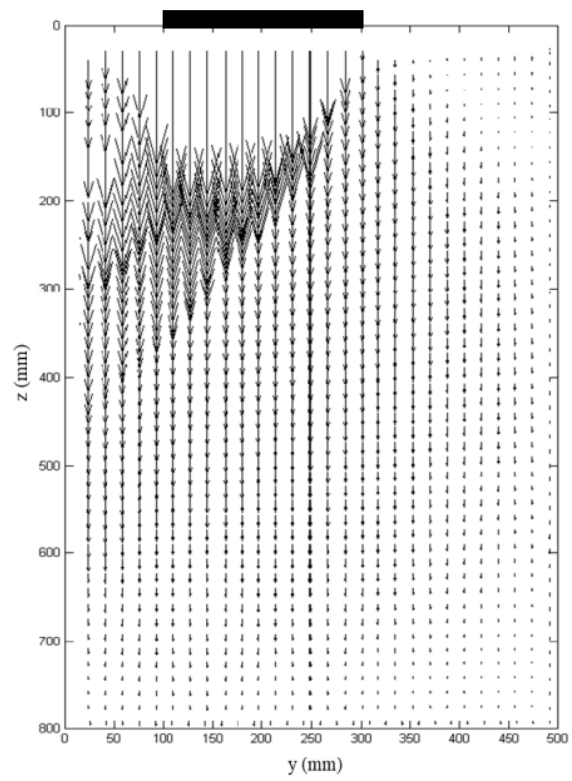

Fig. 4. Displacement fields obtained by PIV analysis for reinforced backfill with 4 layers and flexible face $(\mathrm{dz}=0.08 \mathrm{~B})$ : a) nonwoven geotextile; b) woven geotextile; and c) geogrid. 
a)

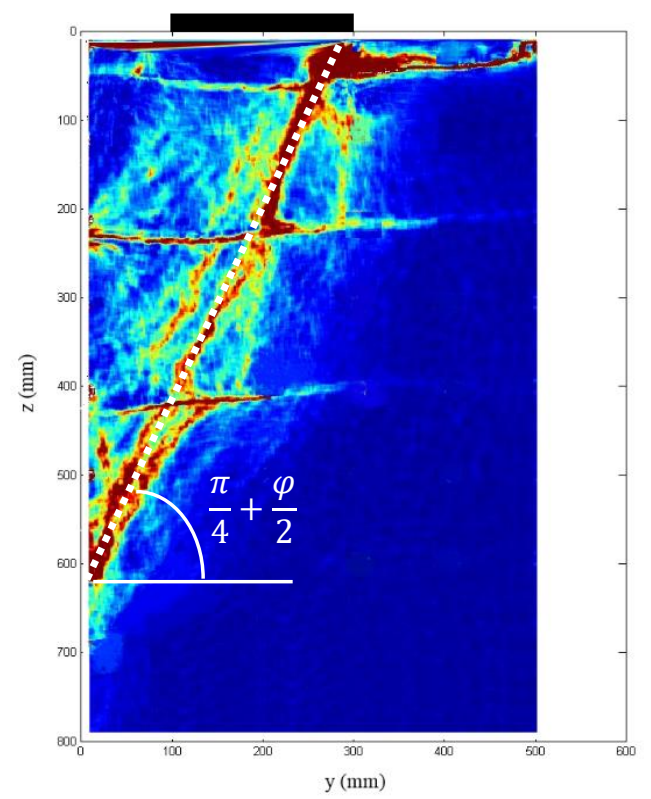

c)

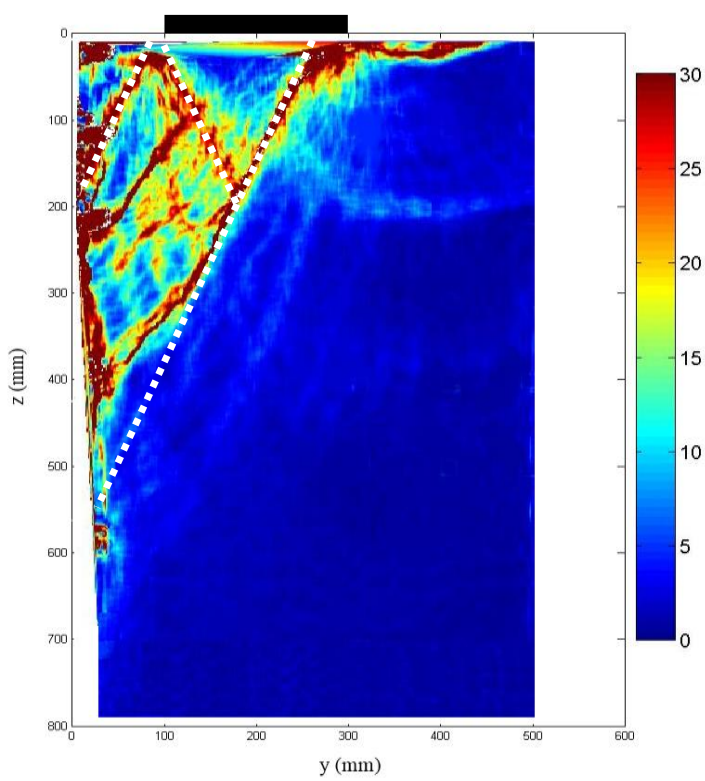

b)

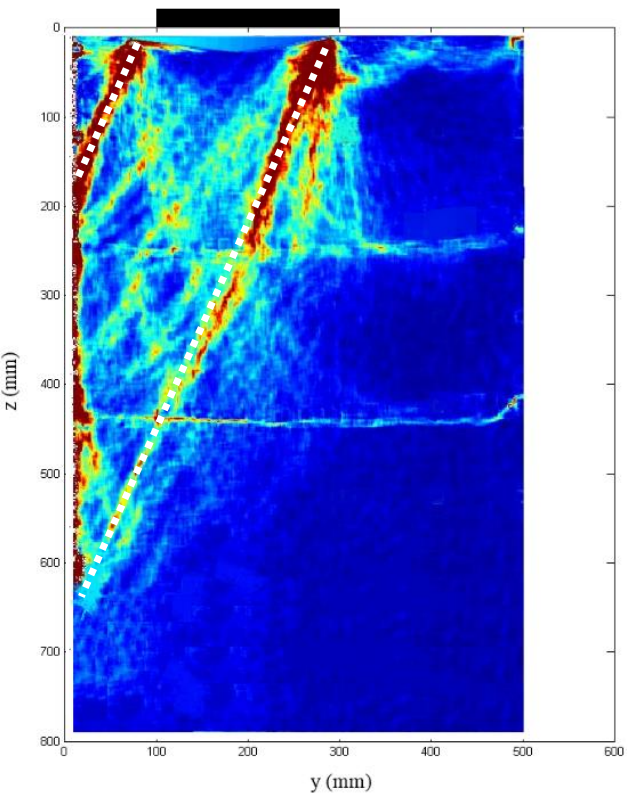

Fig. 5. Total maximum shear strains obtained from PIV data for reinforced backfill with 4 layers and flexible face $(\mathrm{dz}=0.08 \mathrm{~B})$ : a) nonwoven geotextile; b) woven geotextile; and c) geogrid. 
a)

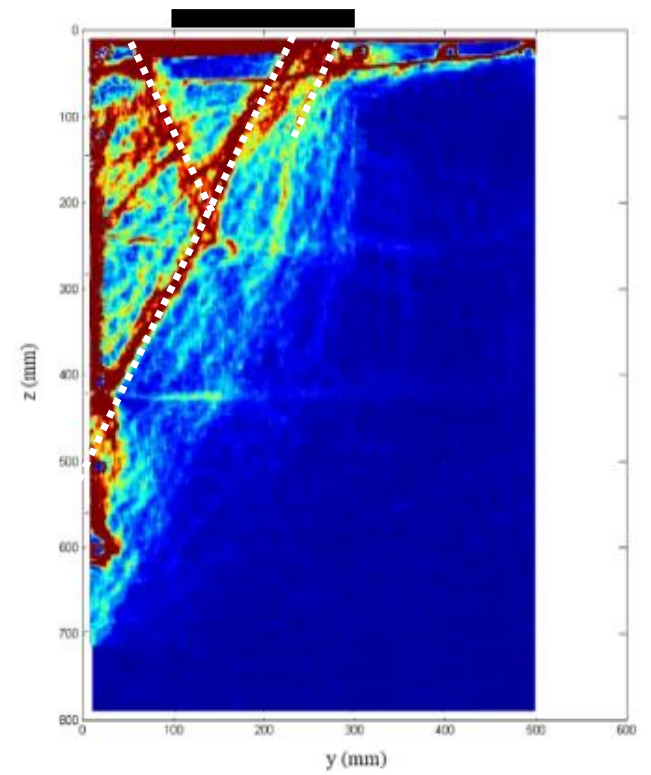

b)

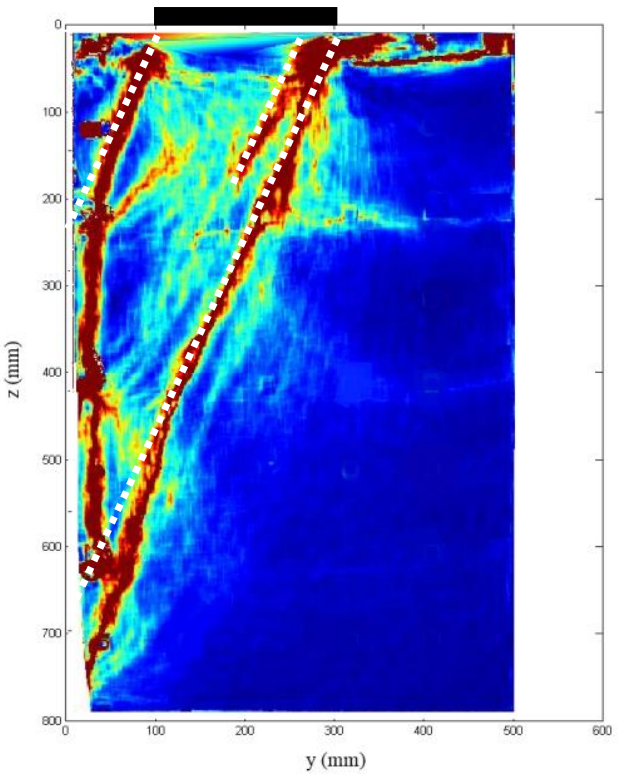

c)

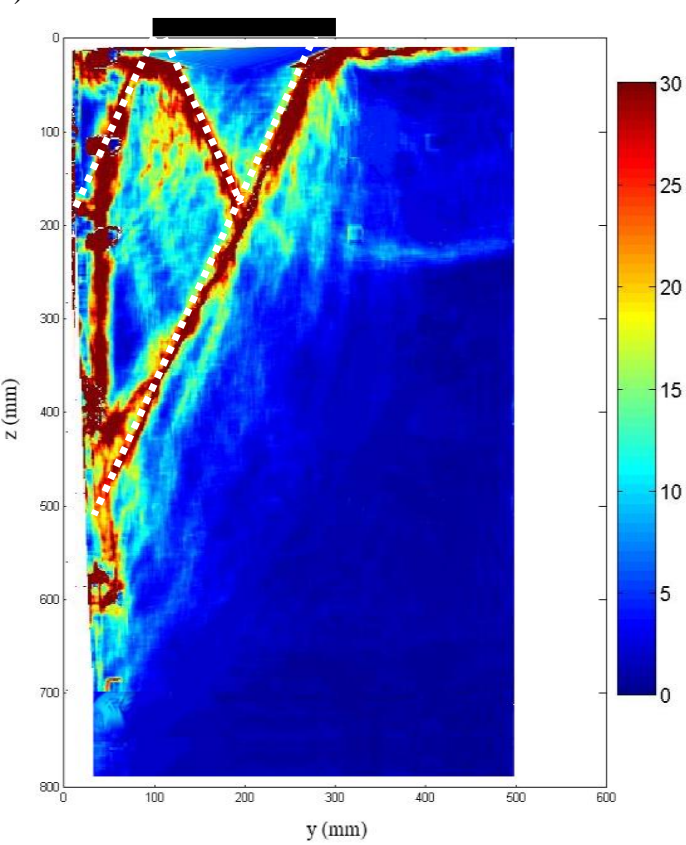

Fig. 6. Total maximum shear strains obtained from PIV data for reinforced backfill with 4 layers and rigid face $(\mathrm{dz}=0.08 \mathrm{~B})$ : a) nonwoven geotextile; b) woven geotextile; and c) geogrid. 
1)

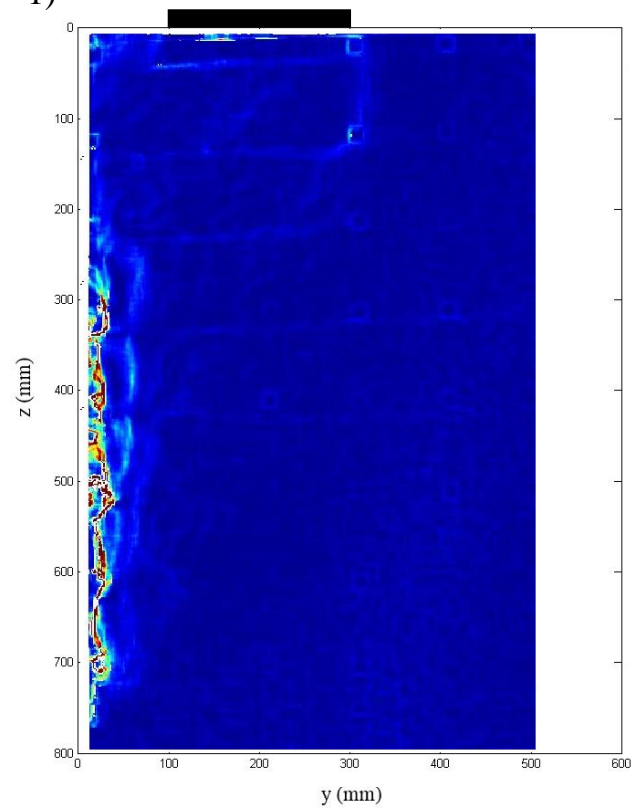

3)

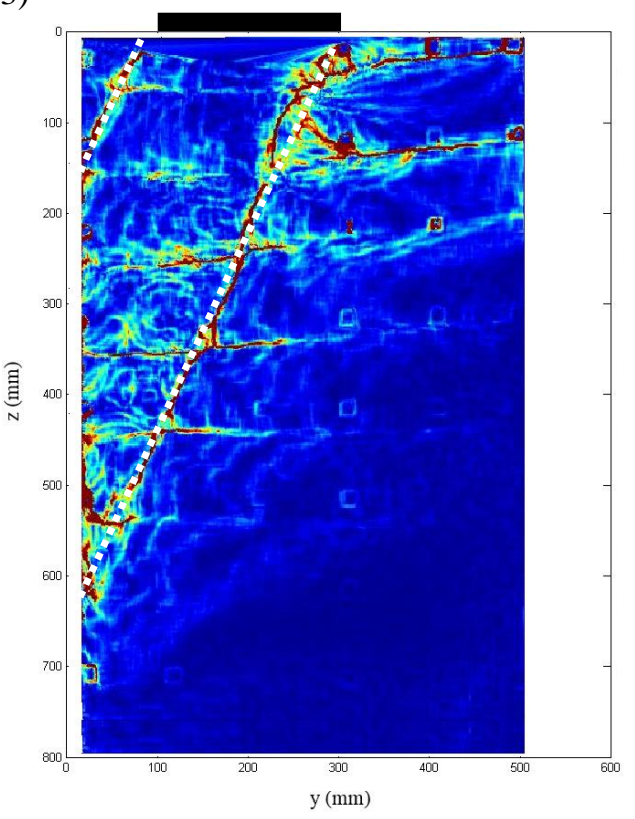

2)

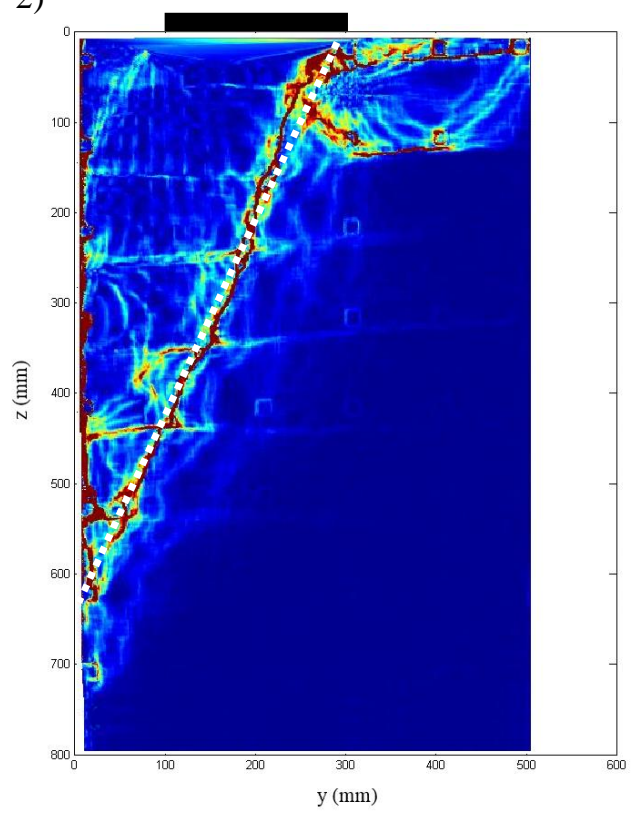

4)

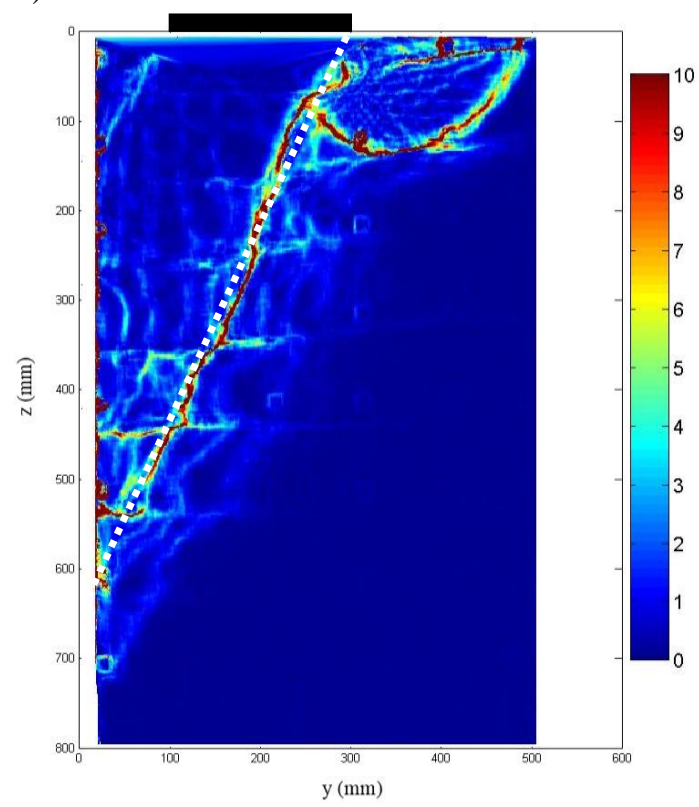

Fig. 7. Creation of shear strain zones by strip footing and flexible facing panel, 4 steps of test, 8 layers-nonwoven-F, plotted in the: a) step 1, end of backfill construction step, after releasing struts in front of wall; b) step 2, end of first loading step (dz=0.08B); c) step 3, unloading step; and d) step 4 , end of second loading steps $(\mathrm{dz}=0.04 \mathrm{~B})$. 
1)

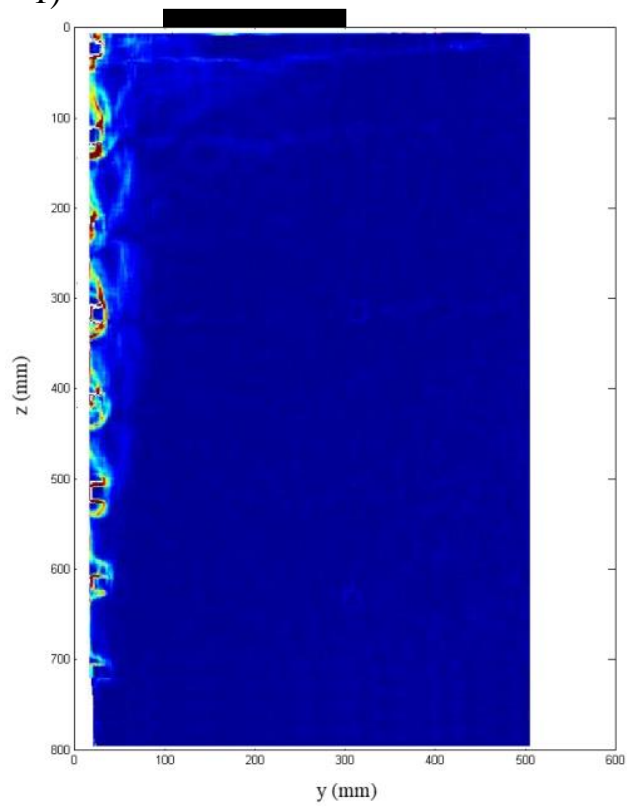

3)

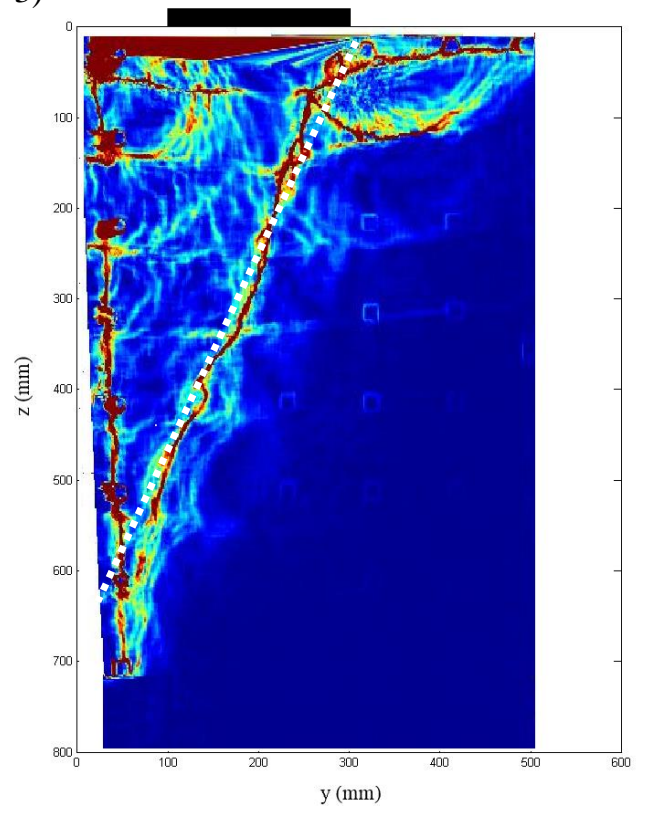

2)

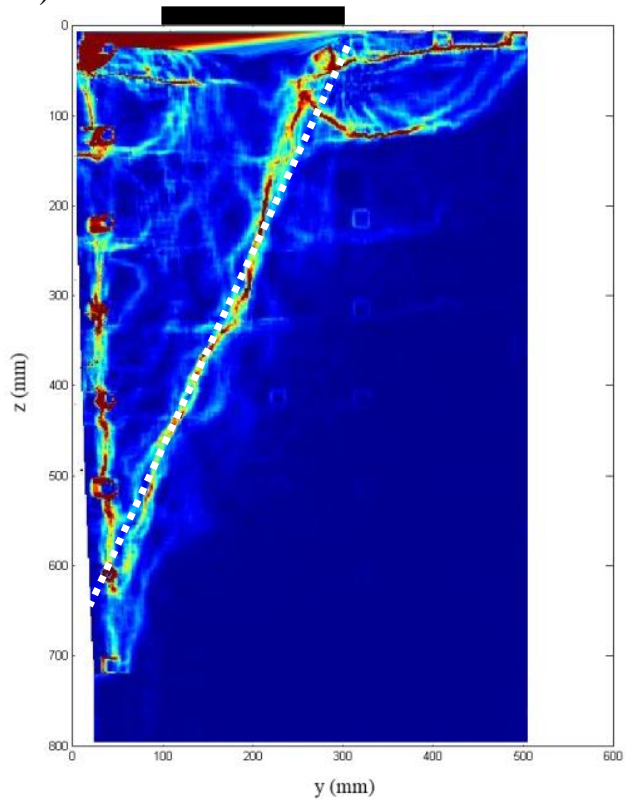

4)

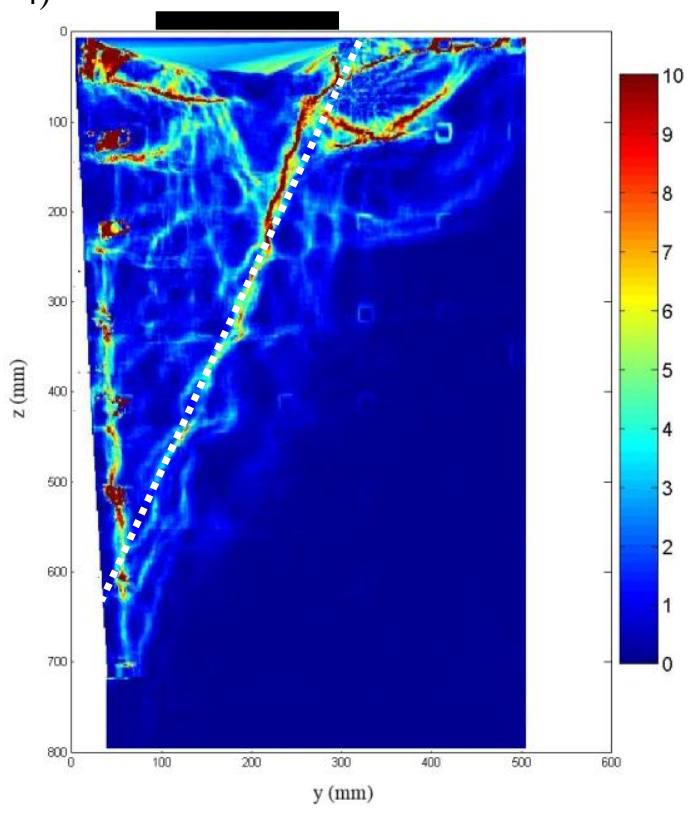

Fig. 8. Creation of shear strain zones by strip footing and a rigid facing panel in face, four steps of test 8layers-nonwoven-R plotted in the end of; 1) end of backfill construction step and after releasing struts in front of the wall, 2) end of first loading steps $(\mathrm{dz}=0.08 \mathrm{~B}), 3$ ) unloading step and 4$)$ end of second loading steps $(\mathrm{dz}=0.04 \mathrm{~B})$. 
Soil pressure-strip footing load

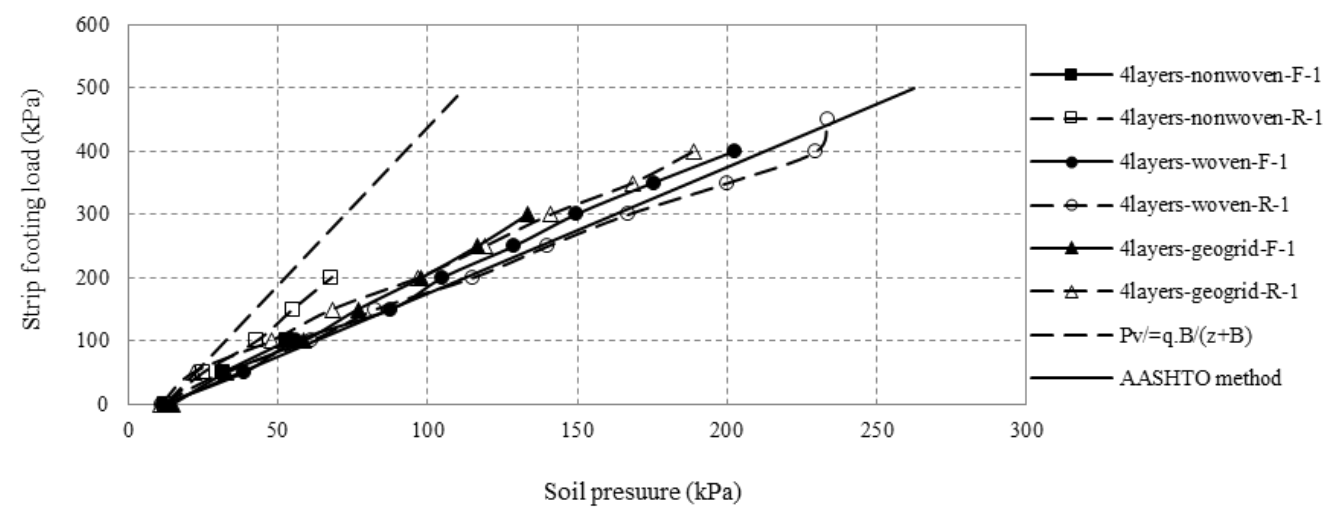

a)

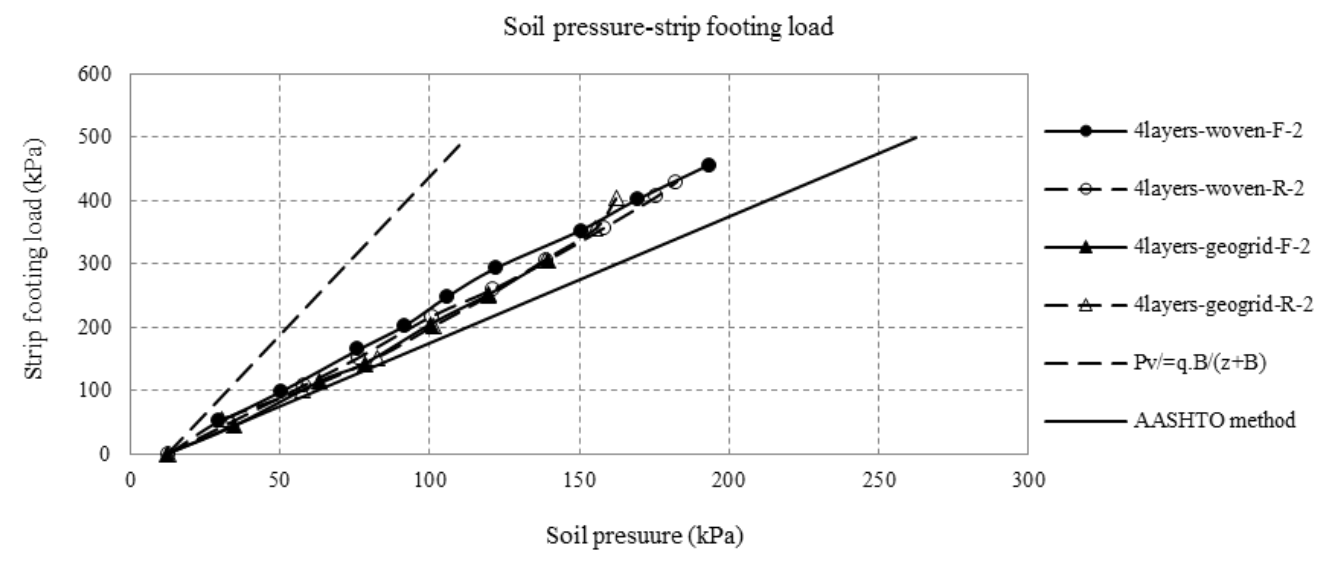

b)

Fig. 9. Vertical earth pressure distribution in the test and empirical methods after applying the strip footing load in rigid and flexible walls with 4 layers; a) first loading step, b) second loading step. 


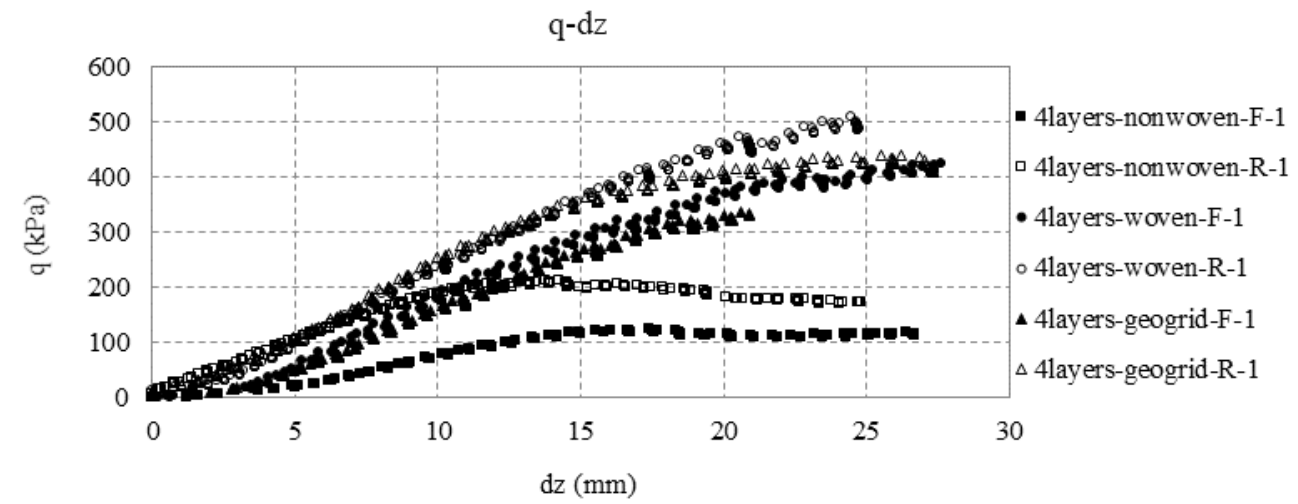

a)

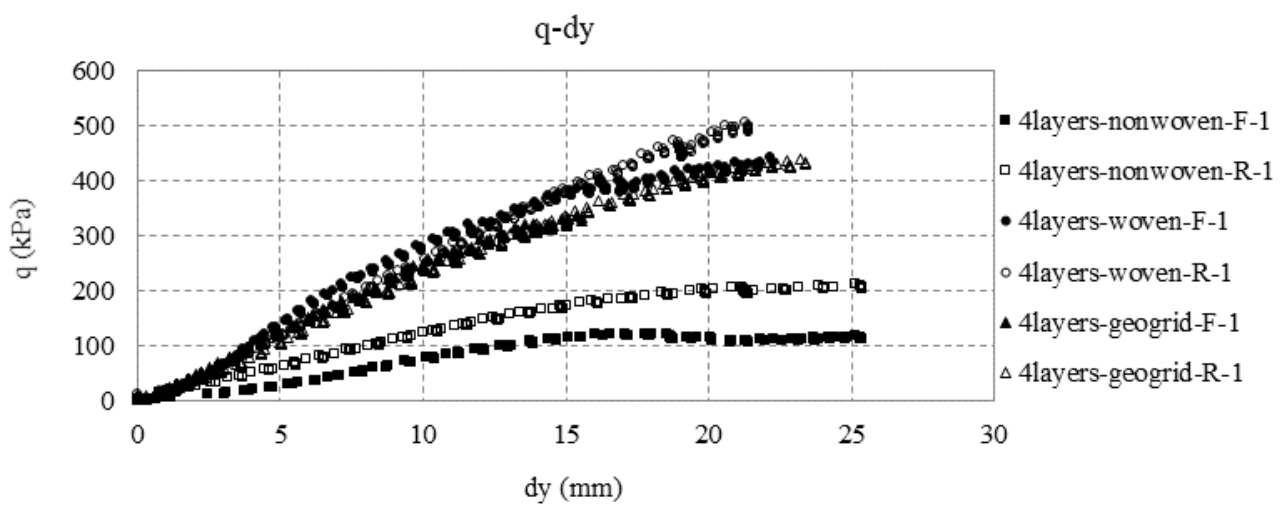

b)

Fig. 10. a) Variations of q-dz, b) q-dy relationship for reinforced backfill with 4 layers. 


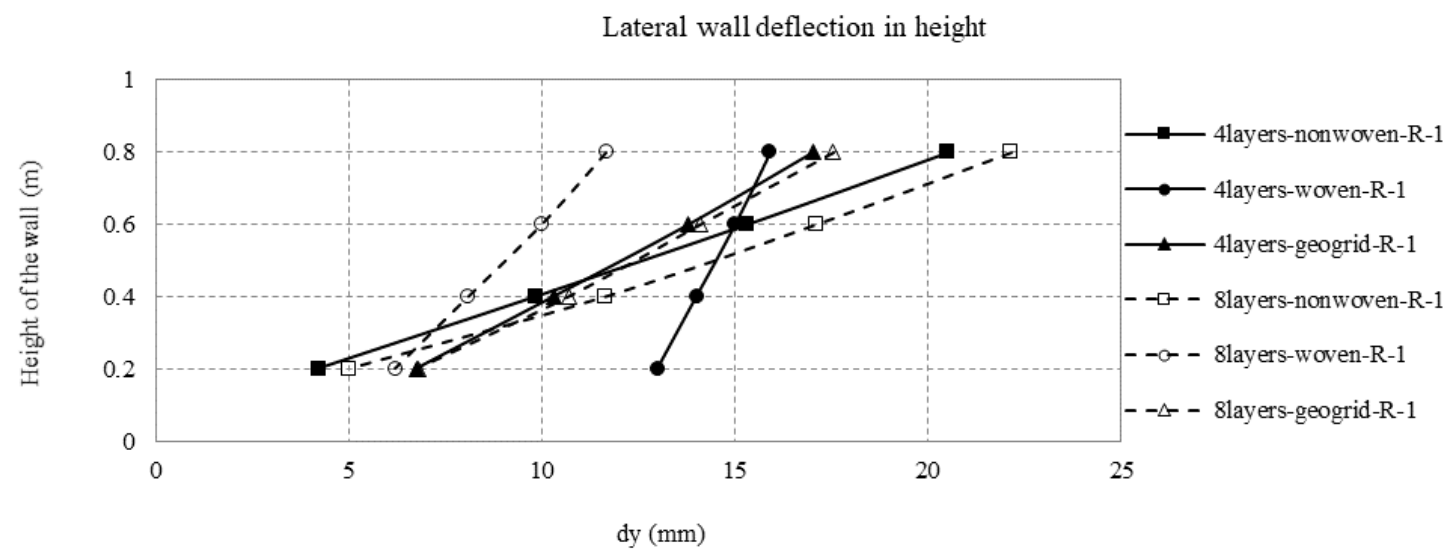

a)

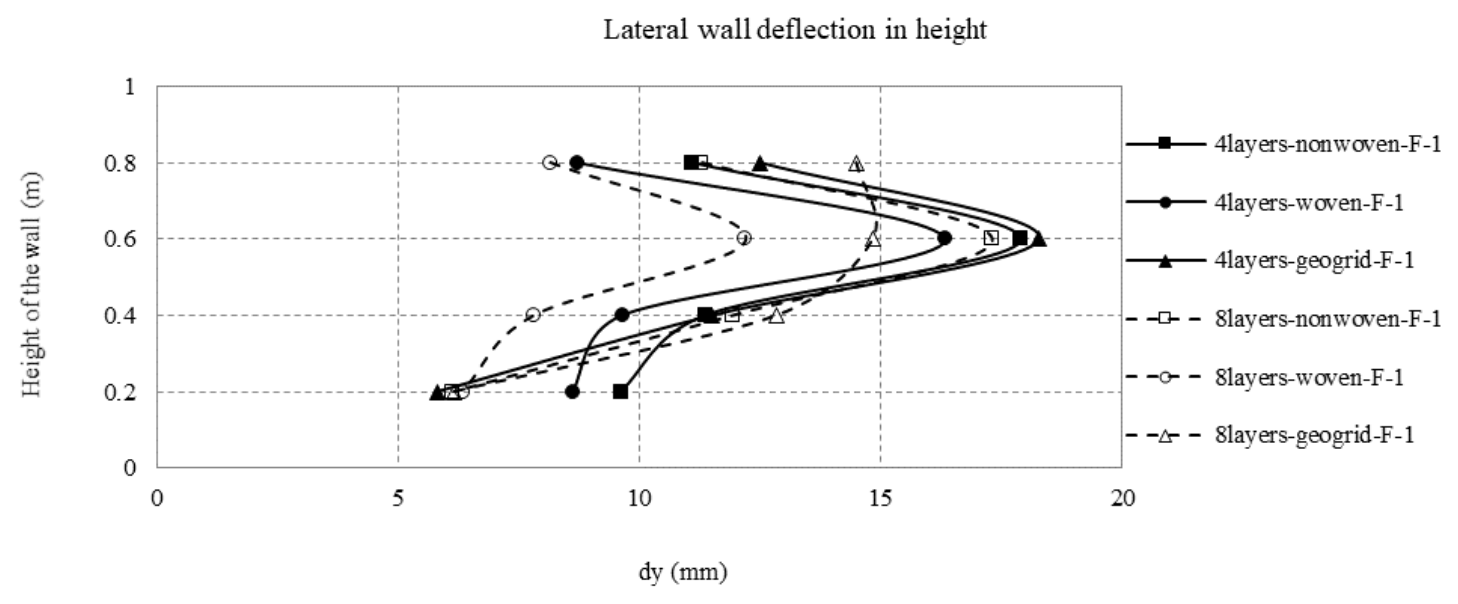

b)

Fig. 11. Lateral wall deflection after applying the same settlement in the strip footing (0.08B); a) rigid face, b) flexible face. 


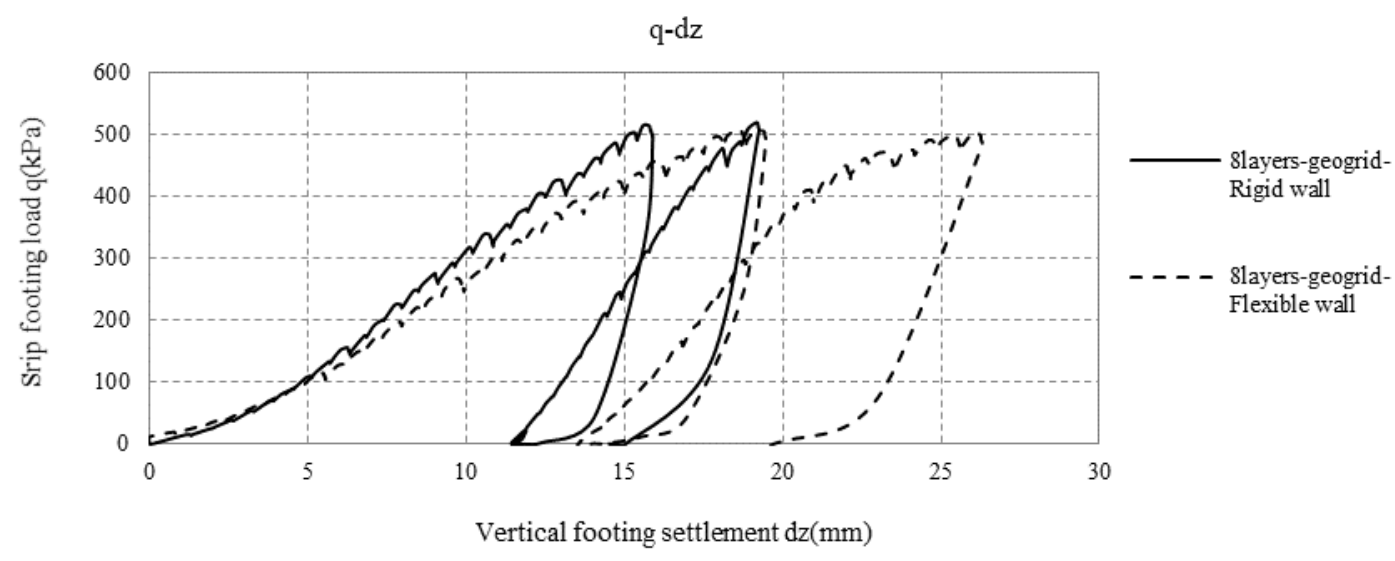

Fig. 12. Strip footing load versus vertical footing settlement for geogrid reinforcement layers in the first loading and second loading steps. 

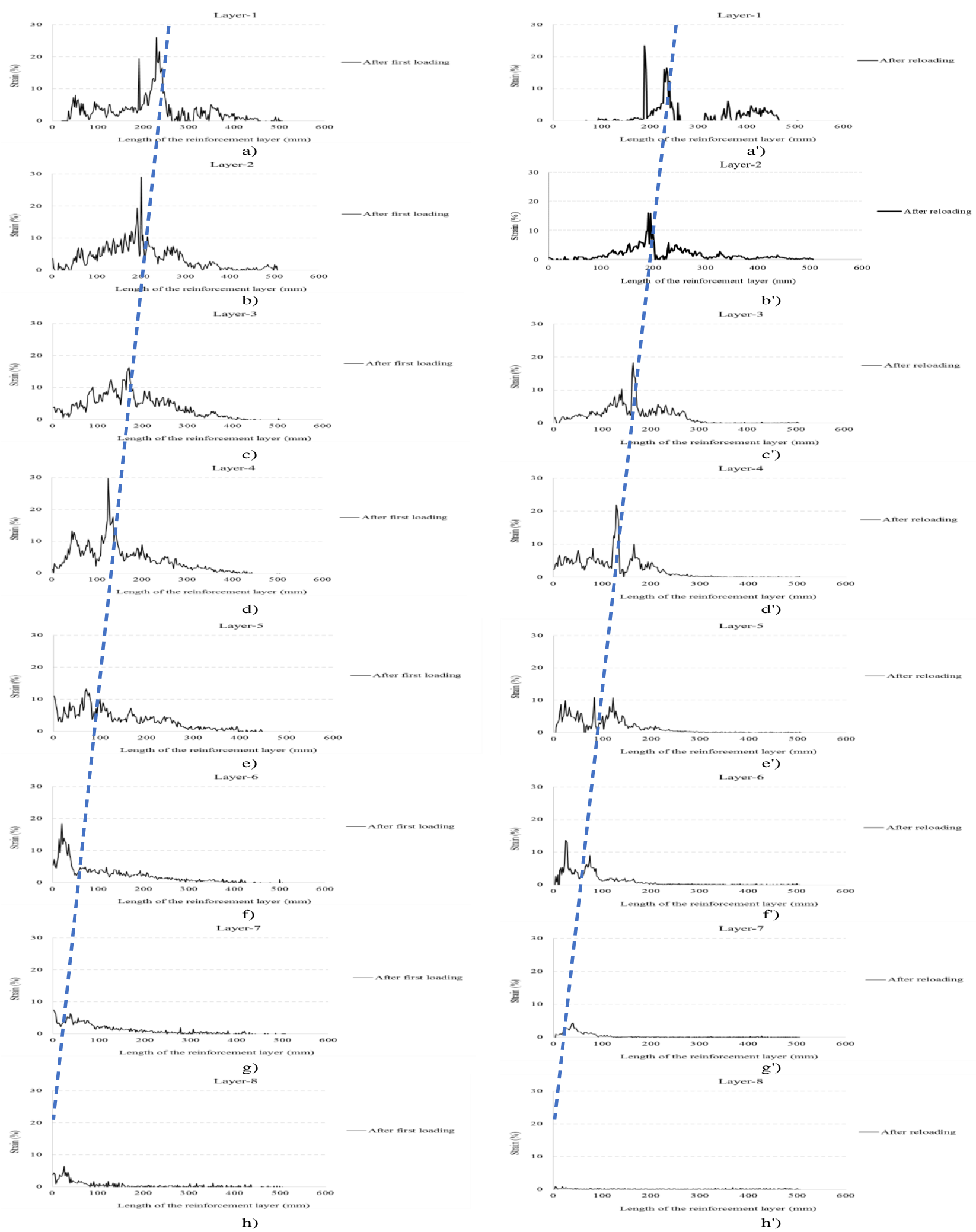

Fig. 13. Strain distribution on the reinforcement layers location from the PIV analysis in the first and second loading steps and in the test with 8 layers nonwoven geotextile, flexible wall; a to $h$ and $a^{\prime}$ to $h^{\prime}$ ) from first to $8^{\text {th }}$ layer. 
